\title{
Networked Professional Learning Communities as Means to Flemish Secondary School Leaders' Professional Learning and Well-Being
}

\author{
Laurien Coenen ${ }^{1, * \mathbb{D}}$, Wouter Schelfhout ${ }^{2}$ and Annie Hondeghem ${ }^{1}$ \\ 1 Faculty of Social Sciences, Public Governance Institute, KU Leuven, 3000 Leuven, Belgium; \\ annie.hondeghem@kuleuven.be \\ 2 Faculty of Social Sciences, Antwerp School of Education, University of Antwerp, 2000 Antwerp, Belgium; \\ wouter.schelfhout@uantwerpen.be \\ * Correspondence: laurien.coenen@kuleuven.be
}

Citation: Coenen, L.; Schelfhout, W.; Hondeghem, A. Networked Professional Learning Communities as Means to Flemish Secondary School Leaders' Professional Learning and Well-Being. Educ. Sci. 2021, 11, 509. https://doi.org/10.3390/ educsci11090509

Academic Editor: Eleanor Dommett

Received: 23 July 2021

Accepted: 1 September 2021

Published: 6 September 2021

Publisher's Note: MDPI stays neutral with regard to jurisdictional claims in published maps and institutional affiliations.

Copyright: (c) 2021 by the authors. Licensee MDPI, Basel, Switzerland. This article is an open access article distributed under the terms and conditions of the Creative Commons Attribution (CC BY) license (https:// creativecommons.org/licenses/by/ $4.0 /)$.

\begin{abstract}
Whereas Professional Learning Communities (PLCs) are a frequently applied professional learning tool in education, their use is often limited to an application among (a) teachers and (b) within-schools. This article contributes to the nascent research evidence on PLC usage for principal professional learning. As outcomes align with PLCs' phased development, this article grasps the learning processes that unfold, the catalyst states that emerge and the overarching role that a process coach can adopt in this collective learning effort. Three distinct PLCs comprising of Flemish secondary school principals were systematically observed over the course of one to two years. In interviews and questionnaires, members $(n=14)$ reported on their experience with PLC activities, group dynamics and their personal professional well-being. Networked learning proved a worthwhile method as positive outcomes of PLC participation were predominantly found in a perceived augmentation of professional well-being and the acquisition of inspiration and ideas. Actual co-construction among principal participants appeared harder to establish as several organisational, group developmental and leadership prerequisites were found to apply. As this study was based on three in-depth case studies, it remains to be confirmed whether its conclusions apply to all school principals in Flanders and can be generalised to their counterparts internationally.
\end{abstract}

Keywords: principal professional learning; principalship; school leadership; professional learning communities; networked learning communities; learning processes

\section{Introduction}

Schools are pre-eminently considered a vehicle for social change and national competitiveness [1,2]. Offering high-quality education in today's diverse and rapidly changing environment, requires schools to adapt to shifting (and often increasing) demands. Keeping up in a successful and sustained way often happens at the expense of principals' professional well-being: Even the highest performing principals in Flanders show signs of burn-out and report on prolonged periods of stress throughout the school year [3]. These findings cause concern as school leadership is considered a key variable in school success and, ultimately, student performance [4-6].

For both managing complex challenges and easing professional grievances, the merits of collegial consulting and networked learning have been recognised by a variety of scholars [7-14]. As continuous professional learning (CPL) is indispensable to keep track of frequent modifications in education [15], collegial consulting and networked learning meet contemporary prescriptions for effective CPL. Recent studies thence emphasise the importance of authentic learning [16], building on prior knowledge [17,18] and, sharing and reflecting on meaningful experiences, thereby (re)activating tacit knowledge [13,19-21]. Moreover, practitioners add meaningful exchanges with peers to their criteria to evaluate formally organised CPL initiatives. 
Despite the advantages of collegial consulting and networked learning-and the necessity for CPL in general-adequate principal preparation and an agreed and thoughtthrough approach to their CPL remain overlooked by policymakers and researchers [3,22-24]. For this reason, this study chose to zoom in on three long-term networked professional learning communities (PLCs) for Flemish secondary school leaders. This study acquires insight into (a) the learning and group dynamical processes, (b) fostering and hindering factors in functional PLC development, and (c) their effects on the CPL and well-being of those involved. Can PLCs meet scholarly expectations in a Flemish setting?

The relevance of this study is fivefold as it targets both methodological and substantive lacunas in the PLC research [25]. First, it deliberately adopts a principal perspective as past research limited its scope to applicability among teachers [26-34]. Second, it focuses on between-school PLCs to foster principals' learning through interaction instead of the commonly employed within-school PLCs [35]. Third, it broadens our understanding of the role a process coach or moderator can fulfil in supporting and facilitating group learning [36]. Fourth, in using systematically acquired observation data, it leaves the commonly taken path of self-reported data and post hoc acquired accounts on PLC functioning [37]. Finally, it applies a multi-method approach in supplementing observations with interviews and questionnaires. These instruments serve to reduce a single method bias [38,39] and grasp in more detail the processes and developments within our PLCs $[25,26]$.

\section{Literature}

Principal CPL encompasses all formal and informal learning activities and processes that equip school leaders with adequate and up-to-date competencies required to thrive professionally [40]. Within the field of education, great value is ascribed to CPL initiatives that allow collective reflection, collegial inquiry and co-creation among peers [41-43]. This section describes PLCs in education: The different stages of (group) development, group learning activities and expected outcomes when PLCs reach optimal functioning. These descriptions and concomitant expectations will guide the analysis section further on.

\subsection{Professional Learning Communities: Theory and Practice}

Considering the complexity [12] and multidimensionality [25,44] of the PLC concept, this study will approach PLCs as a learning design that "involv[es] professionals coming together in a group-a community-to learn" [45], p. 10. This group of professionals "[shares] and critically [interrogates] their practice in an ongoing, reflective, collaborative, inclusive, learning-oriented and growth-promoting way; operating as a collective enterprise" [41], p. 223.

PLCs are based on the assumption that knowledge is situated in day-to-day lived experiences and, made explicit and enhanced through interaction and critical reflection among peers [46]. This assumption applies even more to networked or between-school learning communities. Unlike within-school learning communities, these PLCs unite a wider range of ideas, expertise, experiences and viewpoints as the contexts of principals can differ greatly [35]. A diversity feature that can incite a more qualitative reflection about incremental improvement, making it more likely to find adequate and creative solutions to complex educational challenges $[10,47,48]$. Yet, a scan of PLC literature reveals a predominant focus on within-school teacher CPL [41,46]. Applications of PLCs in a wider variety of settings (e.g., outside education), with a divergent composition (e.g., principals) and intra schools are rare [36].

PLCs, however, do not automatically lead to professional learning and improved practices $[13,35,49]$. Several conditions [27,50] are at play and interplay [51]. The most commonly described conditions to establish promising results are:

- Common goals and approved objectives that help to maintain a focus on concrete outcomes [27] and take collective responsibility thereto [28,52].

- A reflective dialogue through which professionals (a) willingly share relevant professional experiences, questions, concerns, (coping) strategies and material $[28,30,46]$ and 
(b) inquire colleagues about these same elements [30,41,52,53]. Professional inquiry about a deprivatised practice allows reflection and debate in which current practices are questioned, tacit knowledge becomes explicit and, new ideas are disseminated and explored [46].

- A culture of trust, respect, openness and support is indispensable to use prior experiences and knowledge within a group to the fullest and maximise the prospect of interaction [34,41]. Without it, participants might experience discomfort when discussing difficult topics, causing them to refrain from sharing highly relevant experiences [54], which, in turn, limits knowledge acquisition on a group level and hinders a reflective dialogue.

- An intrinsic motivation to engage in a PLC [27] and a firm belief in the relevance it can have for one's practice [31]. This belief will influence an individual's motivation to invest in his or her PLC [20]. Hence, stimulating or hampering processes of learning $[55,56]$.

\subsection{PLC Development: A Complex of Learning Processes and Group Develeopment}

A PLC is not a fixed entity or static feature [57]: PLCs are believed to evolve based on the interaction that occurs within and the accumulation of experiences, ideas, knowledge and reflections [44,58]. Although PLCs' phasal development remains under-researched [59], substantive literature exists on team learning processes that can unfold when collective learning takes place through interaction [60]. In 'construction', 'co-construction' and 'constructive conflict', Decuyper et al. [61] discern three basic team learning processes. Construction refers to the articulation of individual experiences with and opinions on the problem situation and how to deal with it. PLC members get to know each other's strengths, weaknesses, learning needs and questions as members open up their private practice. This sharing phase is characterised by careful listening to and a sound understanding of group members [42].

Co-construction can be described as the collaborative construction of meaning by adding to, refining, building on or modifying the individual input from the previous phase [62]. "The outcome of this process is that 'new' meanings, which were not previously available to the group, emerge in collaborative work" [42], p. 287.

Constructive conflict-also criticism and feedback-implies an incorporation of diverse ideas and divergent viewpoints through critical yet constructive reflection and debate. Differences in opinion should not be considered a paradox or even an emotional rejection, but an opportunity to elicit debate, learn and challenge existing believes to improve professional practices [63]. The activation of different views and competing interpretations might lead to a richer argumentation and, new perspectives that ensure more creative and possibly suitable solutions to a shared problem [39,64].

Team learning processes-and the hierarchical build-up therein-however, do not arise automatically nor unconditionally. Raes et al. [56] showed the occurrence of learning processes to parallel stages of group development. When a PLC steadily grows from a collective of individuals into an effective functioning social system, social states arise in its wake $[56,65]$. These catalyst emergent states (CES) [61] are deemed strong predictors of effective collective learning $[39,61]$. CES relevant to this study are:

- Team psychological safety indicating the "taken-for-granted beliefs about how others will respond when one puts oneself on the line, such as by asking questions, seeking feedback, reporting a mistake or proposing a new idea" [60] (p.352). In order to feel psychologically safe, a culture of respect and trust among PLC members is indispensable $[34,66]$. Such a culture is even considered the best predictor of the occurrence of team learning processes $[33,39]$ as learning is facilitated by openness, being allowed to think freely and experiment.

- Cohesion might refer to either social cohesion or task cohesion. In the case of the former, it indicates emotional bonds between group members such as friendship, liking and caring. Social cohesion motivates to helping each other succeed. Task 
cohesion on the other hand refers to the pleasure an individual and the group as a collective receive from completing an objective. Group members are motivated and committed to the task and regulate their behaviour toward its end [39].

These conditions especially apply to networked PLCs in which members are unacquainted and group development processes start from scratch [27]. Participating principals are, not directly dependent on the professional and organisational success of other principals and their schools, although they can draw inspiration and learn from their experiences [39,67].

In that regard, the PLCs studied in this study function as 'groups' rather than genuine 'teams', which are characterised by an interdependency between its members and a shared responsibility for the outcomes of their teamwork [55]. Whereas we do recognise the conceptual difference between groups and teams, the so-called difference between 'teamsin-theory' and 'teams-in-practice' [68], we deliberately do not delve into this conceptual debate. Instead, we base ourselves on work by Vangrieken, Dochy and Raes [33] to justify the adoption of terminology from team learning research. According to the authors, 'group' and 'team' should not be considered a dichotomy but a continuum, depicted by the term 'team entitativity' or the degree to which a group functions as a team. It is, therefore, reasonable to study collaborations between educational professionals using team learning concepts. Yet, for the sake of accuracy and conceptual clarity, we will denote 'team learning processes' as 'learning processes' (LPs) and 'team psychological safety' as 'group psychological safety' throughout the remainder of this study.

\subsection{PLC Development: A Matter of Conscientious Guidance}

Research often stresses the importance of leadership within PLCs [54,56,69]: a person to guide the learning processes, steer activities and facilitate an open and trusting climate [70]. Not only can he or she-henceforth called 'process coach'-influence the occurrence of LPs for the better or worse [42,56], bad guidance also significantly lowers participants' satisfaction with the CPL initiative and their perceived knowledge and skills acquisition $[26,27,36]$. However, the role of a process coach goes unclarified in many studies.

A process coach can adopt the role of expert, coach and/or coordinator [26]. As an expert, (s)he provides information and answers content-specific questions. As a coach, (s)he focuses on stimulating reflection and learning among group members. (S)he proceeds as a team facilitator and pays attention to group development processes [42,56]. (S)he slows time for mutual understanding, professional inquiry and connecting the shared stories. (S)he thereby ignites critical yet constructive debate for which (s)he convinces the team of the added value of difference, conflict but also failure as these all constitute windows of learning opportunity [71]. As a coordinator, (s)he structures the meetings according to the groups' predefined goal, leaving room for exchange, discussion and reflection [27]. (S)he keeps track of logistical arrangements and avoids a standstill of merely sharing personal anecdotes and/or frustrations without ever moving towards in-depth reflection and actual co-creation [71]. (S)he makes sure all participants (can) contribute equally.

Similar to LPs, the role of a process coach is believed to alter as PLCs mature and activities within progress [57,70]. Margalef and Roblin [72] showed how process coaches particularly assumed a coordinator role at the start. As sessions progressed, their role shifted towards a coaching interpretation. Little is known, however, about the exact interplay between LPs and process coaches' roles, especially in PLC arrangements for school principals.

\subsection{Collective or Networked Learning and Professional Well-Being}

The evidence base on PLC outcomes reveals that PLCs can raise a feeling of connectedness among participants [73]. Articulating and discussing pertinent work-related issues with peers allows identification and recognition [74]. Both are believed to reduce stress and self-doubt $[3,75]$ whilst increasing self-efficacy $[73,76,77]$. When members receive feedback 
and find support in PLCs, this might render a positive-and thus reducing-effect on perceived emotional and professional isolation [53,78]. High levels of professional isolation are, moreover, associated with lower levels of professional well-being (e.g., job satisfaction and motivation) and eventually higher scores on burn-out indicators $[79,80]$. Collaborative activities and the social support found therein can increase job enthusiasm, satisfaction and motivation [44] and, the confidence one has in his or her job [7]. Participation in PLCs-and similar forms of group coaching - is, furthermore, believed to facilitate (teacher) professional learning $[13,26,27,32,34,81]$ and render concrete tools or material [82,83]. Notwithstanding several of these findings were derived from teacher and within-school PLC set-ups, we hypothesize similar tendencies using principal networked PLCs.

Visually summarizing, this literature section leads the subsequent parts of this study to describe and qualitatively asses the following model (Figure 1):

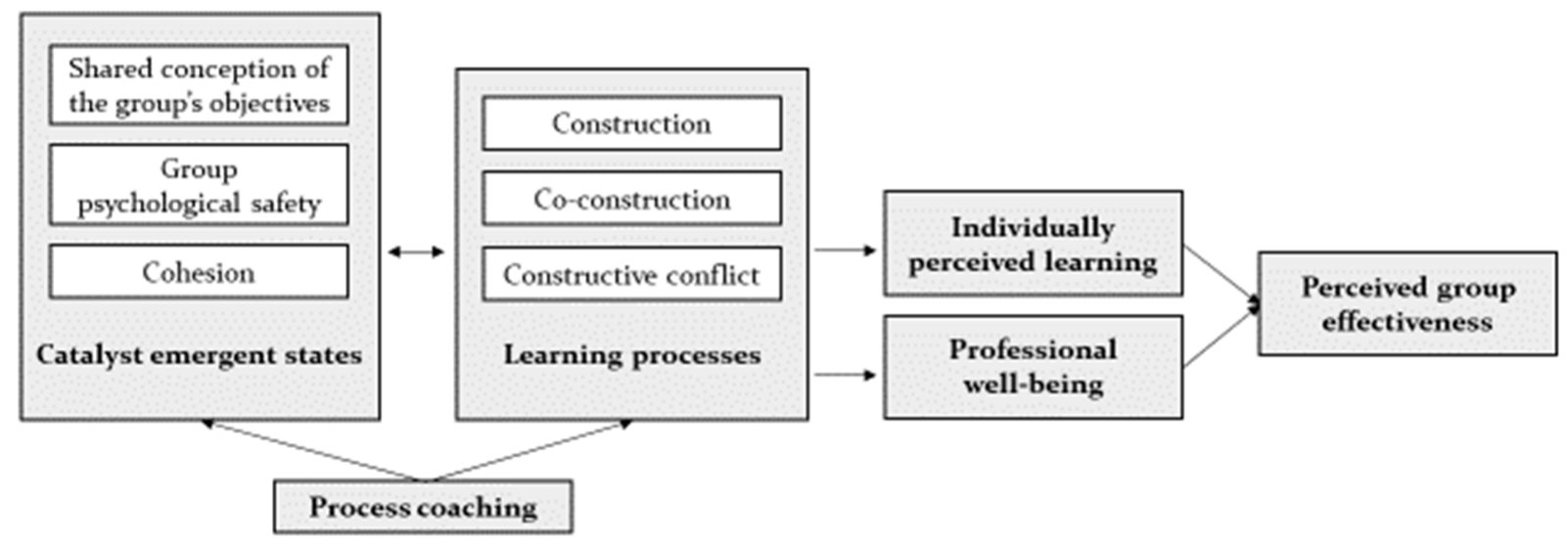

Figure 1. Proposed model.

\section{Research Questions}

Given the state of research on PLCs in general and its use in school principal professional learning in particular, this study addresses (a) the potential output and outcomes a principal PLC can generate, (b) favourable or necessary conditions under which these outputs or outcomes arise, and (c) the role of the process coach. The research questions (RQs) central to this study are:

1. RQs. concerning PLC output and outcomes

a. To what extent can PLCs contribute to the professional well-being of Flemish secondary school leaders?

b. To what extent can PLCs contribute to the individual professional learning of Flemish secondary school leaders?

2. RQs. concerning the conditions for successful principal PLCs

a. How do learning processes (LPs) within PLCs (i.e., construction, co-construction and constructive conflict) emerge and evolve over time?

b. How do the group developmental factors (i.e., CES) of social and task cohesion, group psychological safety and a shared perception of the group's values and objectives associate with the occurrence of LPs within PLCs?

3. RQs. concerning the role of a process coach

a. Which role (i.e., expert, coach and/or coordinator) do the process coaches fulfil within the PLCs and how does this relate to PLC processes and outcomes?

b. Does the role of the process coaches alter over time?

An answer to these questions will help the reader identify conditions under which PLCs can grow into a worthwhile method for principal CPL. It hence offers pedagogical guiding services and organisers of CPL practical evidence and recommendations for future 
school principal PLC design: how to successfully implement, maintain and sustain a principal PLC?

\section{Materials and Methods}

The subsequent section describes the chosen longitudinal mixed-method case study design and relates it to three methodological gaps in PLC research.

\subsection{A Longitudinal Mixed-Method Approach}

We observed three distinct networked PLCs for Flemish secondary school leaders as organised by the educational network for Cities and Municipalities (OVSG). Two of the PLCs were part of a professional learning trajectory that aimed at school innovation through reflexive dialogue among peers. In these PLCs, principals discussed and exchanged policy approaches to distributed leadership at their schools. All OVSG secondary education principals-both mainstream secondary as well as special secondary-were invited to register for this initiative. Thirteen principals out of 68 partook. These were divided into two PLCs: A mainstream and a special education learning community. We followed these over the course of six and nine sessions that were organised approximately every three months between May 2018 and May 2020.

The third PLC was embedded in an existing network that the City of Antwerp organises for its schools. The network of secondary education principals gathers every two weeks to discuss pertinent educational issues and legislative updates. Every other timeand thus once a month - the network was organised according to PLC principles. Four learning communities were created to collectively reflect on and create tools to administer (a) personnel, (b) language and (c) evaluation policy or (d) the new educational quality framework by the inspectorate. We captured four sessions within the latter PLC between September 2019 and October 2020. This PLC comprises seven principals.

All three of our cases are convenience samples in which participants were either selfselected or obliged to partake. This study applied a mixed-method approach in which, per case, quantified observation accounts are supplemented with quantitative questionnaire data and qualitative data acquired from semi-structured interviews. Each method and corresponding analysis technique is discussed hereafter.

In using systematically and first-hand acquired observation data, this study deviates from the commonly taken path of self-report data and post hoc acquired accounts on PLC functioning [37]. A frequently occurring single method bias is, furthermore, reduced by the multi-methods approach this study applies as it supplements the observation data with data from interviews and a questionnaire [38,39]. This approach also helps to grasp more in-depth the processes and developments within the PLCs $[25,26]$. Collective learning is context-sensitive [84], therefore, qualitative accounts and measures are needed to grasp individual professional learning within a PLC-and thus a particular context [85]. Finally, whereas multiple studies on PLCs report on short term trajectories such as two to seven weeks, this paper targets three long-term trajectories that comprised of one and two years of observation data which allows for descriptions of evolutions over time.

\subsection{Learning Community Set-Up}

In each PLC, principals were brought together to reflect on a pertinent educational challenge, discuss with and learn from one another. The PLCs proceeded similarly. During the first session and under the supervision of the process coach, principals decided which element concerning respectively policy approaches to create distributed leadership by means of creating learning communities (PLCs 1 and 2) and the reference framework for educational quality (PLC 3) they wanted to address. Subsequent sessions were built around these self-chosen topics. The duration of sessions approximated two hours.

In the first two cases, the PLC was led by an external process coach associated with the University of Antwerp. He led the trajectory process-wise and content-wise. In addition, the PLCs were attended by two (i.e., PLC1) or three (i.e., PLC2) pedagogical counsellors 
working for the pedagogical guidance services of the educational network OVSG. Within the trajectory, these pedagogical counsellors served as an external source of information and a principal's first point of reference when questions or problems arose related to PLC content. The third PLC was led by an internal process coach as one of its principals voluntarily took this responsibility. Similar to the principals in PLC 1 and 2, the principals in PLC 3 received help too from an external source of expertise. Their PLC was attended by one pedagogical counsellor who provided background information on the new framework and hinted at tools or overview documents already put together for use by the educational network. Both the external process coach and the internal process coach were trained in guiding PLCs. They had a clear vision of what was expected of them and what needed to happen within the communities [35]. Moreover, in both PLCs 1 and 2, we found one pedagogical counsellor to also assume a process coaching role in support of the external process coach. A practical consideration explains this divide: The pedagogical counsellor concerned was expected to take over the PLC's leadership and continue its activities from schoolyear 2020-2021 onwards. Such a role extension did not occur in PLC 3.

In PLCs 1 and 2 principals signed up voluntarily and out of personal motivation. They were not (well-)acquainted and sessions were held by rotation in their respective schools. In PLC 3, principals were obliged to take part in the PLC set-up, albeit were allowed to choose freely from four thematic groups. Sessions were held in a fixed location in Antwerp. As principals both knew each other beforehand and participation in the network was expected, the attendance rate was clearly higher in PLC 3 (i.e., 86\%) than in PLCs 1 and 2 (i.e., $73 \%$ and $64 \%$ ).

Even though similar in duration, leadership and overarching purpose, the PLCs varied in terms of their main objective, composition (i.e., number of principals enrolled, attendance rate, acquaintance with fellow principals and, principals' background and motivation to partake) and geographical location. Table 1 provides an overview of PLC characteristics. Subsequent case introductions outline the particular nature of each case.

Table 1. Professional learning community (PLC) and principal participant characteristics.

\begin{tabular}{|c|c|c|c|}
\hline Feature & PLC 1 & PLC 2 & PLC 3 \\
\hline Main objective & $\begin{array}{l}\text { Organisational innovation in line } \\
\text { with learning } \\
\text { community principles }\end{array}$ & $\begin{array}{c}\text { Organisational innovation in line } \\
\text { with learning } \\
\text { community principles }\end{array}$ & $\begin{array}{c}\text { Policy and tool development for } \\
\text { the new framework on } \\
\text { educational quality }\end{array}$ \\
\hline Composition & & & \\
\hline Number of principals & $7(10)^{1,2}$ & $8(12)^{1,2}$ & $7(8)^{2}$ \\
\hline Attendance rate & $73 \%$ & $64 \%$ & $86 \%$ \\
\hline Acquainted & Yes-rudimentarily & No & Yes-well \\
\hline Principal background & Special secondary & Mainstream secondary & Mainstream secondary \\
\hline Process coach(es) & 2-External & 2-External & 1-Internal \\
\hline Location & Flanders-various locations & Flanders-various locations & Antwerp-fixed location \\
\hline Duration & & & \\
\hline $\begin{array}{l}\text { Timeframe } \\
\text { Sessions }\end{array}$ & May 2018-May 2020 & May 2018-May 2020 & September 2019-October 2020 \\
\hline $\begin{array}{l}\text { Sessions } \\
\text { Freguency }\end{array}$ & 9 sessions & $6(5)^{3}$ sessions & 4 sessions \\
\hline $\begin{array}{l}\text { Frequency } \\
\text { Scheduled session duration }\end{array}$ & Every 3 months & Every 3 months & Every month \\
\hline \multicolumn{4}{|l|}{ Demographics (at start trajectory) } \\
\hline Gender-female principals & $71.4 \%$ & $62.5 \%$ & $71.4 \%$ \\
\hline Years of principal experience & 4 years and 4 months & 5 years and 8 months & 7 years and 6 months \\
\hline $\begin{array}{l}\text { Experience in leading position } \\
\text { outside education }\end{array}$ & $14.3 \%$ & $37.5 \%$ & $\mathrm{~N} / \mathrm{A}$ \\
\hline
\end{tabular}

${ }^{1}$ Two mainstream secondary school principals also partook in the special secondary school principals' PLC as their schools were confronted with similar problems (e.g., a high proportion of students with special educational needs). ${ }^{2}$ The number between brackets indicates the total number of participants in a PLC (i.e., including the external process coach(es) and/or pedagogical counsellors). ${ }^{3}$ Although six sessions were observed, one session comprised of only one principal, two pedagogical counsellors and a process coach. As this session's set-up resembled individual coaching, it was omitted from further analysis.

\subsubsection{PLC 1: Case Context and Background}

The first case comprises a diverse participant group. Eying the participants' school background, on the one hand, several combinations of so-called 'types' and 'education finalities' in special secondary education were represented in the PLC (e.g., a school offering instruction that equips students with autism or emotional and behavioural problems with 
skills to the labour market whilst another prepared the same group for higher education). Moreover, these educational formats were offered by a variety of personnel teams as they differed in size (i.e., ranging from a small team of only 30 staff members to a large team of 168 staff members), collaboration culture and openness to innovate their educational practice. The latter differences between the represented schools became apparent from both the participating principals' accounts on their teams' functioning and current school culture and, descriptions of the exact same elements as offered from a third-party perspective-that of the pedagogical counsellors.

Looking at participating principals' personal background, on the other hand, differences in years of school leader experience (i.e., ranging from less than one year to eleven years), motivation to enrol and expected benefits from participation existed. The intake interviews revealed acquiring inspiration and new ideas about pertinent policy challenges to be the main driver to register for the PLC trajectory. Whereas participants appeared highly motivated to partake, six out of eight principals indicated that to them, the PLC's objectives were not particularly clear at the start. The pedagogical counsellors, moreover, pointed out significant differences in the leadership styles and views of our participants.

The underlying objective of this PLC was to learn from one another through collective reflection and initiating co-creation about a pertinent innovation challenge in education: Initiating distributed leadership in schools according to learning community principles. Throughout the sessions, participating principals were stimulated by the process coaches to consider policy lines related to the self-chosen topics (i.e., individual process planning and evaluation policy and, how to successfully report those to the inspectorate) in terms of activating personnel to take collective responsibility. The pedagogical counsellors helped them critically asses the possibilities to initiate such a collective effort given the characteristics of their school teams (e.g., openness to innovate and collaborative culture).

To accustom participants to the idea of organising schools as genuine learning communities, theoretical intermezzos were provided by the process coach on two occasions (i.e., a $30 \mathrm{~min}$ lecture during the first session and a $45 \mathrm{~min}$ one during the seventh). Principals within the PLC were acquainted through the principal platform organised by OVSG for its special secondary school principals but were not members of the same school community.

\subsubsection{PLC 2: Case Context and Background}

Within the second case, diversity is primarily situated in participants' expectations about the PLC's operations and what to acquire from them. Even though-and similar to PLC 1-the trajectory's objectives were perceived unclear, the majority of principals did confirm a prior belief in the added value of PLC participation to their professional lives. This finding is mirrored in the fact that principals seemed to have formulated their own - sometimes diverging — expectations about PLC operations and output. Whereas all principals mentioned inspiration, new ideas and perspectives as something they aspired to acquire from the good practices of others, three out of six (i.e., the novice principals) merely perceived this as a step towards professional self-assurance. The three more experienced principals, on the contrary, began with clear learning needs and policy-related questions (e.g., the new inspectorate). To them, gaining inspiration only implied a first step towards a concrete end: A well-thought-out (policy) plan or completely worked-out materials to implement. The years of experience principals had in their jobs ranged from 1 year to 12 years.

Looking at principals' school background, PLC 2 comprised of a well-balanced mixture of schools: All mainstream education tracks were evenly represented (i.e., general, technical, vocational and arts secondary) in what can be considered two smaller (i.e., less than 300 students), two medium (i.e., between 300 and 600 students) and two larger schools (i.e., 600 or more students). Hence, schools also evenly varied in staff size (i.e., ranging from 50 staff members for the smallest to 138 staff members for the largest school). Apart from one, all personnel teams, although often described as wayward, were found willing to take collective responsibility. For all except one, the pedagogical counsellors furthermore 
believed in participants' leadership ability to steer innovation according to distributed leadership principles. Significant differences in leadership styles and views did not become apparent from the interviews.

PLC 2 followed the same objectives (i.e., both main and underlying) and had a similar line-up (i.e., purposeful incorporation of pedagogical counsellors as a source of external advice) and set-up (i.e., group reflection and discussion alternated with theoretical intermezzos) as did PLC 1 . In the case of the latter, theoretical intermezzos were provided at three points in time (i.e., a $60 \mathrm{~min}$ lecture during the first session, a $30 \mathrm{~min}$ one during the fourth and a $15 \mathrm{~min}$ one during the last session). Unlike PLC 1, however, principals were entirely unacquainted.

\subsubsection{PLC 3: Case Context and Background}

PLC 3 followed the same rationale as PLCs 1 and 2 (i.e., gather principals to collectively learn and mutually reinforce professional and/or school practices), yet differed in finality. PLC activity was directed at the narrowly defined objective of co-creating a tool to interpret, orderly store, visualise, follow up on and communicate about quality standards and supporting policy documents required by the inspectorate's new framework. Collective learning, therefore, depended on the group's ability to interpret the framework's requirements and expectations, while a mutual reinforcement of participating principals ${ }^{\prime}$ practice rested on the design of a workable instrument to integrate those. In contrast to PLCs 1 and 2-which were very much directed at learning and improvement through sharing good practices-PLC 3 commenced with a more outspoken co-creative focus. Post-hoc interviews, furthermore, confirm all principals to have started the PLC with this central objective in mind and perceived their colleagues to have done so too.

Not only were principals well-acquainted they also operated in a similar environment as their schools did not vary much in size (i.e., 480 to 670 students) and were all located in the city centre of Antwerp-often in highly diversified and/or socially deprived neighbourhoods.

\subsection{Instruments}

As observation schemes, surveys and interviews are used to measure the specific aspects of each research question, Table 2 provides an overview of the aspects measured and incorporated per instrument. The exact connections between instrument items or questions and the measures presented in Table 2 are further explicated to the reader in Supplementary Files A-C.

\subsubsection{Observations and Observation Scheme}

Observations were conducted by one researcher who attended 19 sessions (totalling $34.5 \mathrm{~h}$ of observations). Without partaking in the discussions, the researcher audiotaped the sessions and kept low inference logs about the dynamics observed among participants. For each session, an observation scheme was filled out afterwards. The observation scheme divides each session into sequences of $15 \mathrm{~min}$. Consistent with the theoretical framework, the scheme counted the times LPs and certain role behaviour by the process coaches occurred per sequence. LPs were mapped through the Team Learning Beliefs and Behaviour Scale (TLBBS) by Van den Bossche et al. [42]. From this scale, we derived nine objectively observable items and added an additional two that directly connected to the specific objectives of our three PLCs. The process coaches' role behaviour was observed through eight items connected to the roles of 'Expert', 'Coach' and 'Coordinator'. 
Table 2. Instruments used for data collection.

\begin{tabular}{ccccc}
\hline Variables and Measures & Observation Scheme & $\begin{array}{c}\text { Survey } \\
\text { Principals }\end{array}$ & Interviews Principals & $\begin{array}{c}\text { Interviews } \\
\text { Pedagogical Counsellors }\end{array}$ \\
\hline Learning processes (LPs) & $\mathrm{x}$ & & & \\
Construction & $\mathrm{x}$ & & & \\
Co-construction & $\mathrm{x}$ & $\mathrm{x}$ & & \\
Constructive conflict & & $\mathrm{x}$ & $\mathrm{x}$ & $\mathrm{x}$ \\
Catalyst emergent states (CES) & & $\mathrm{x}$ & $\mathrm{x}$ & $\mathrm{x}$ \\
Group psychological safety & & $\mathrm{x}$ & $\mathrm{x}$ & \\
Cohesion (social and task) & & & $\mathrm{x}$ \\
Shared conception objectives & $\mathrm{x}$ & & $\mathrm{x}$ \\
Group effectiveness & $\mathrm{x}$ & & $\mathrm{x}$ \\
Leadership & $\mathrm{x}$ & & $\mathrm{x}$ \\
Perceived value & & $\mathrm{x}$ & $\mathrm{x}$ \\
Role 1-Expert & & $\mathrm{x}$ & \\
Role 2-Coach & & & \\
Pele 3-Coordinator & & & \\
Practical output & & $\mathrm{x}$ & \\
\hline
\end{tabular}

An overview of scale items within the observation instrument is provided in Supplementary File A. Due to the small n, the analysis of our quantified observation data is conducted under a Poisson probability distribution.

\subsubsection{Questionnaire}

A questionnaire consisting of 36 items was self-prepared to assess participants' professional well-being (i.e., job satisfaction and self-efficacy), perception of catalyst emergent states (CES) (i.e., group psychological safety, social cohesion, task cohesion and shared conception of the group's objectives) and the perceived group effectiveness.

Principals in PLCs 1, 2 and 3 completed the questionnaire after the PLC's final session (i.e., June 2020). As the questionnaires preceded the interviews, its descriptive statistics were not as much used in the final analysis but primarily served to guide the closing interviews and direct interview questioning (cf. infra). All variable items as well as information on the validated instruments they were derived from are found in Supplementary File B.

\subsubsection{Interviews}

In each PLC, interviews were held with the pedagogical counsellors and participating principals. These interviews allowed multiple perspectives on past PLC proceedings. In PLCs 1 and 2, the principal interviews were organised both at the start of the PD trajectory (i.e., October 2018) and after (i.e., June-July 2020). In the first series of interviews, principals were questioned about their professional well-being, motivation to enrol and what they hoped to acquire from participation. In the closing interviews, they were presented with their answers from the first round of interviews: Were their expectations fulfilled and did their well-being alter noticeably because of the PLC? In the interviews, principals furthermore reflected on PLC proceedings. PLC 3 participants on the other hand only partook in a closing interview and reflected in retrospect on whether their expectations were fulfilled. Interviews with the pedagogical counsellors were also only held at the end of the trajectory. The questions from both interview protocols are included in Supplementary File C.

The duration of the interviews took 59 min on average, rendering a total of $15.9 \mathrm{~h}$ of audiotaped data. All interviews were transcribed verbatim and analysed via NVivo 12. The a priori codes, derived from the theoretical framework, coded by are presented in Table 2. For an overview of exemplary codes and coding statistics, the reader is referred to Supplementary File D.

\subsection{A Case-Study Analysis}

A case-study approach guides and structures our subsequent analysis. The analysis section is hence divided into three subsections, each corresponding to a PLC case. A standardised way of analysis is chosen throughout this section as each subsection starts by discussing the observation data. The analysis proceeds by adding data from the ques- 
tionnaires and interviews, from both participants and process coaches, to provide detail and/or nuance. To avoid needless repetition, Section 5.1 (relating to PLC1) includes two summative tables (i.e., Tables 4 and 5) that are to be referred back to when reading Sections 5.2 and 5.3 as both also incorporate descriptive statistics from PLCs 2 and 3.

Given the in-depth analysis of our three cases, the research is of an exploratory nature. Summary answers to the research questions, including a comparison between the three cases and the formulation of hypotheses, are stated and set off with regard to existing research in the discussion. Readers can limit their reading by moving straight to the discussion and conclusion sections.

\section{Results}

\subsection{PLC 1-A Networked Community of Special Secondary Eduction Principals}

\subsubsection{LPs and CES at Play ad Interplay}

In Figure 2, panel (a) displays the evolution in frequency with which construction, co-construction and constructive conflict activities averagely occurred per sequence of each session. Meanwhile, panel (b) provides an indication of the contribution both process coaches made to the previous frequency figures. The difference between panels (a) (overall activity) and (b) (process coach activity) indicates how actively involved principal participants got over time. Considering the last session, for example, panel (a) shows that on average almost ten construction activities occurred per sequence of $15 \mathrm{~min}$. Of those, a bit more than two were initiated by the process coaches. Whereas principals were very active on a construction front during this specific session, they were less active when it came to co-construction activities: Nearly all of those were initiated by the process coaches.

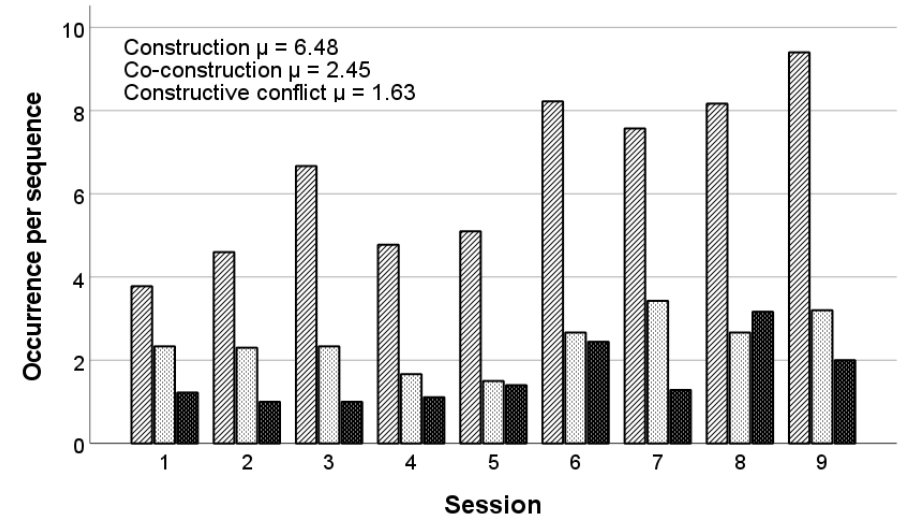

(a)

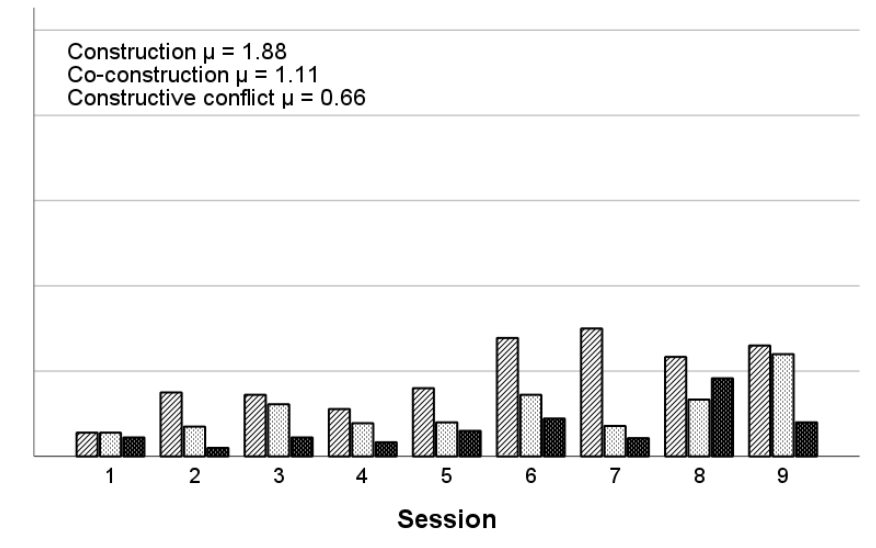

(b)

Figure 2. Evolution in the average occurrence of LPs per sequence (a) and LPs initiated specifically by both process coaches (b) within PLC 1. Legend of LPs represented.: $\square=$ construction activities on average per sequence; $⿴ 囗 ⿱ 一 一)=$ co-construction activities on average per sequence; = constructive conflict activities on average per sequence:. Note (1). The frequencies presented in Figure 2, panel (b) are based on the activity span of two process coaches. Note (2). ' $\mu$ ' expresses the average occurrence of each LP type over the course of nine sessions.

From Figure 2, panel (a) appears that although the activity span broadened over the course of nine sessions, the nature of LPs did not as the proportion between all three LPs remained approximately the same. Table 3 confirms the first part of this conclusion: Activities within each LP cluster were observed more frequently as sessions progressed, albeit only the positive evolution in construction activities reached statistical significance. The chance of observing a mere 25 construction activities over the course of a whole session (like we did at the start of the trajectory) when in reality the average occurrence of construction activities per session over time reached 50 , equates to $0.01 \%$. These findings 
suggest that the construction type of activities increased considerably over the course of nine sessions.

Table 3. Occurrence pattern of LPs within PLC 1.

\begin{tabular}{ccccc}
\hline $\mathbf{L P}$ & $\boldsymbol{\lambda}$ & $\mathbf{t}(\mathbf{k} \rightarrow \mathbf{k})$ & $\begin{array}{c}\text { Observed Start } \\
\text { Value }\left(\mathbf{X}_{\text {start }}\right)\end{array}$ & $\begin{array}{c}\text { Probability }\left(\mathbf{X} \leq \mathbf{X}_{\text {start }}\right) \\
\sim \text { Pois }(\boldsymbol{\lambda})\end{array}$ \\
\hline Construction & 50 & $2^{\prime} 19^{\prime \prime}$ & 25 & $0.0001^{* * *}$ \\
Co-construction & 19 & $6^{\prime} 07^{\prime \prime}$ & 18 & 0.4695 \\
Constructive conflict & 12 & $9^{\prime} 14^{\prime \prime}$ & 9 & 0.2424 \\
\hline Overall & 81 & $1^{\prime} 32^{\prime \prime}$ & 56 & $0.0021^{* *}$ \\
\hline
\end{tabular}

Note (1). $\lambda$-values were calculated based on an average session duration of 7,6 sequences or 115 min. As none of our sessions took precisely this long, the $\lambda$-values are extrapolations based on the occurrence of construction, co-construction and constructive conflict activities as observed over the course of a session. Note $(2) . t(k \rightarrow k)$ pertains to the time between the occurrence of events $(\mathrm{k})$ expressed in minutes and seconds. Note (3). $\mathrm{P}\left(\mathrm{X} \leq \mathrm{X}_{\text {start }}\right)$ expresses a within PLC comparison under $\lambda$. Legend. ${ }^{*}=p<0.05,{ }^{* *}=p<0.01,{ }^{* * *}=p<0.001$.

Regarding the second part of the conclusion (i.e., the nature of LPs), we found that while PLC members, in time, engaged significantly more in construction activities, they did not entirely parallel this engagement co-construction and constructive conflict wise. Although from a PLC developmental point of view, the basic building blocks were available (i.e., principals willing to open up their practice and share their experiences with fellow principals), the PLC did not evolve towards drawing conclusions from the ideas and practices exchanged, neither generally nor more specifically applied to the context of one or more participants' schools. An in-depth reflection and/or discussion on concrete applications, which would require a critical approach, was rather avoided. As a consequence, the average occurrence of co-construction and constructive conflict activities did not differ significantly from the value we observed for both during the first session. The significant increase in overall LP activity shown in Table 3 can entirely be explained by the increase we witnessed in construction activities.

From Figure 2, panel (b) can be derived that the process coaches' involvement in LPs remained high throughout the sessions. On average, as much as $29 \%$ of construction activities, $45 \%$ of co-construction activities and $41 \%$ of constructive conflict activities observed, were initiated by either two. These figures are, however, unsurprising as they merely signify their effort to stimulate participants to co-constructive endeavours or to provoke them to provide each other with feedback. Why did this prove so difficult? Three factors intertwine. From the interviews emerged that firstly, principals felt more at ease restricting themselves to sharing individual bits of information and ventilating frustration:

Principals receive a lot of satisfaction out of the fact that they can sit together and talk endlessly about their jobs. Developing a good relationship among each other, for them, appears very important. Something therapeutical almost. And therapeutical is fine but it has its limits: at some point, things need to actually happen [ ... ] and they find it very difficult to select things [of what has been shared therapeutically] to implement in their schools (pedagogical counsellor 5-female).

Secondly, personal traits and learning preferences kept some principals from actively engaging, which impacted LPs:

[Principal 10] learns by simply being present and listening. He absorbs: A sponge that takes things with him. Yet, it is not give-and-take: He will partake when you ask him to, but it always strikes me that content-wise, he scores very badly. He repeats the same story whereas the others actually add something every now and then (pedagogical counsellor 5-female).

Thirdly, principals' expectations appeared to interfere with the PLCs objectives as some principals relied heavily on active interventions from both the process coach and pedagogical counsellors. They expected someone to challenge them with a direct line of 
questioning on school affairs and/or tell them what to implement and how to, rather than collectively construct a solution themselves. That way, principal 4 (female- 11 years of experience) related:

I thought [the process coach] very understanding and sympathetic towards us and our schools, but when it comes to feedback which made you really think for a moment, for me, that should have been more.

Whilst realising:

We were ten adults, right? [10 adults] who played a waiting game: 'We'll see who takes the lead'. Yet, no one did. We always waited politely for each other to finish. That is not only the responsibility of the ones who lead the conversation.

It thence proves utterly important to map participants' expectations and attune them to the PLCs objectives prior to its start. Not only should these objectives be clear and clearly structured, but they also require frequent repetition and brushing-up. For principal 8 (female - two years of experience) even indicated that she 'forgot how it all began' when questioned about the PLC's objectives. Moreover, PLC proceedings are believed to benefit from a better understanding and stronger ties between group members. It seems that due to a lack of shared goals, principals restricted themselves to a story-telling about their personal experiences (and frustrations). They were less inclined to (1) think about and co-construct a school policy approach concerning distributed leadership and (2) be too critical of themselves and even less so of colleagues.

Although (some) principals were already acquainted, Table 4 shows that social cohesion within the group was only attributed a fair score of 0.91 after the completion of sessions. This appraisal made it hard to truly probe each other and enter into thought-provoking debate, in spite of the psychological safety within the PLC being perceived as good.

Table 4. Descriptives of CES and group effectiveness as averagely perceived.

\begin{tabular}{cccc}
\hline & PLC 1 & PLC 2 & PLC 3 \\
\hline CES & $\mu(\boldsymbol{\sigma})$ & $\mu(\sigma)$ & $\mu(\sigma)$ \\
\hline Group psychological safety & $1.31(0.40)$ & $1.44(0.43)$ & $1.70(0.26)$ \\
Social cohesion & $0.91(0.44)$ & $0.90(0.52)$ & $1.00(0.20)$ \\
Task cohesion & $0.33(0.27)$ & $-0.133(0.38)$ & $0.75(1.10)$ \\
Shared conception of group objectives & $0.33(0.19)$ & $0.27(0.60)$ & $1.08(0.96)$ \\
\hline Group effectiveness & $0.48(0.57)$ & $0.95(0.62)$ & $1.06(0.69)$ \\
\hline
\end{tabular}

Note. All variables imply composite measures based on a 5-point Likert-scale. Values range from -2 (e.g., not psychologically safe at all) over 0 (e.g., adequately safe) to 2 (e.g., perfectly safe).

\subsubsection{Process Guiding}

As the process coaches clearly had a prominent part to play throughout the sessions, what role did they adopt specifically and can we discern an alteration over time? Figure 3 indicates the roles of coordinator, expert and coach to follow an occurrence pattern without an explicit alteration over time. Nonetheless, most prominent appeared the coaching role for, on average, $73 \%$ of sequences contained one or more coaching interventions (i.e., compared to the $68 \%$ and $58 \%$ for, respectively, the coordinating and expert interventions we observed). 


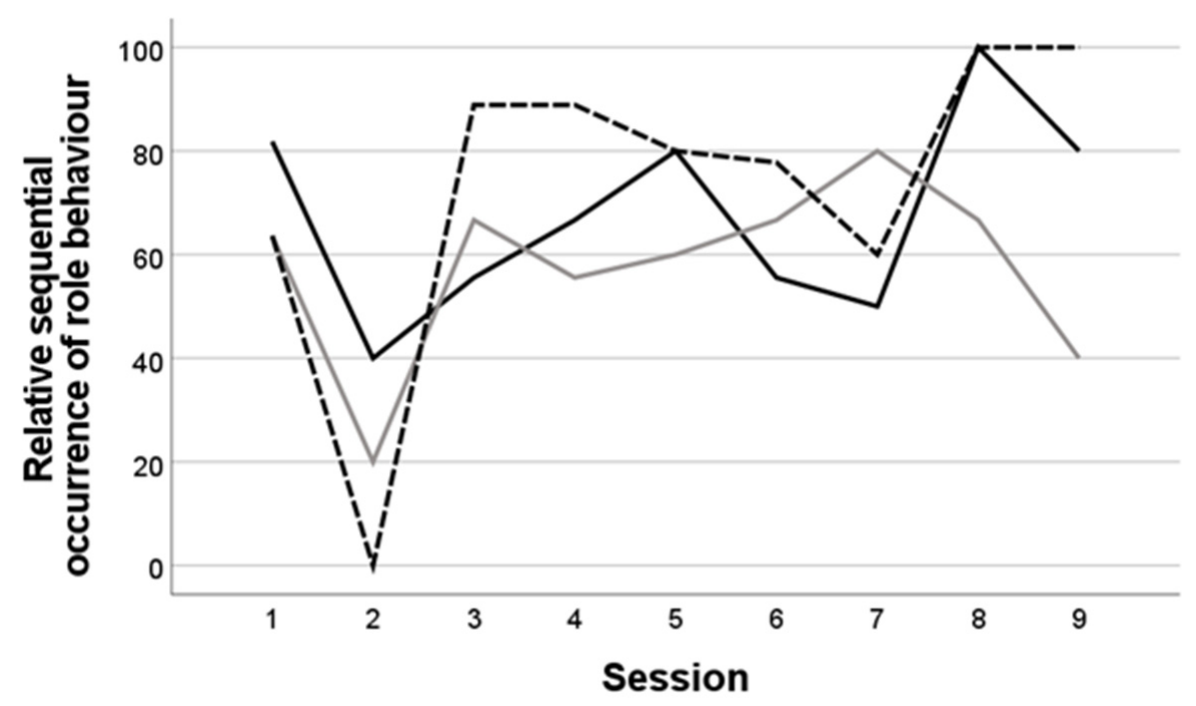

Figure 3. Evolution in the process coaches' role behaviour over sessions within PLC 1. Legend. Black line $=$ coordinating role; grey line $=$ expert role; dotted line $=$ coaching role. Note. These figures are based on the activity span of two observed process coaches.

Overall, the participating principals appreciated the process coach's expert role and deemed his interventions both interesting and adequate, while the coaching role-as related earlier when discussing principals' expectations-could have been played out more. Yet, from the interviews became clear that participants missed a coordinating interpretation most as they felt that discussions were at times too loosely lead and/or meetings could have done with a more structured preparation (i.e., clear agenda including the minutes from the last meeting, a reappraisal of objectives and preparatory assignments if need be). For example:

The process coach to me served to keep us focused: 'Do you recall this or that', really a theoretician who, based on our [shared] examples could put us on our way. However, the end product was too inadequate to truly call it a success (principal 12-female-7 years of experience).

Remarkably, we often observed how principals were explicitly asked to share material with the group so that these could be discussed during the next session. These requests were, however, rarely ever met. Principals' call for more coordination and structure does consequently not parallel their actual behaviour: The limited amount of arrangements made during sessions were not considered important or pressing enough to complete in between sessions.

Finally, whereas the process coach was generally perceived to add to the group development and LPs, this did not always apply to the pedagogical counsellor assuming that role:

I tend to believe [the pedagogical counsellor's] knowledge hampered. From the knowledge base she has, she wanted to provide additional clarification too quickly but that stifled the debate among us (principal 12 - female -7 years of experience).

A thin line appears to exist between too little and too much steering of PLC proceedings.

\subsubsection{To Participate or Not to Participate: PLC Output and Outcomes}

According to Table 5-and building on the prior findings-the added value of PLC participation is firstly situated on a social or 'therapeutical' front. Since the PLC, principals felt professionally less isolated and had a stronger sense of acknowledgement as they were given the opportunity to ventilate both frustrations and concerns about their school challenges. 
Most of the time, when you toss something in the group, you find that you are not the only one with this problem. That, in itself, is sometimes a consolation (principal 7-male-less than one year of experience).

Indicated or mentioned less often in respectively the questionnaires and interviews were practical outcomes of PLC participation. While principals indicated to have drawn inspiration from colleagues' experiences and acquired some knowledge element on distributing leadership or initiating and maintaining learning communities, they signalled answers to the specific policy-related questions they had at the start were missing. Principals, furthermore, lacked a substantive exchange of tools and materials that sparkled the aforementioned inspiration in the first place. Sharing, as they felt, was often too limited to story-telling.

Sharing documents, I tell you: I feel as if I was left empty-handed (principal 8 -female-2 years of experience).

Despite clear points for improvement, nearly all principals did indicate they were inclined to remain if the PLC were to continue. Moreover, a belief in the added value of the PLC also became clear indirectly. Whereas eight sessions were originally planned, an additional ninth was scheduled at the request of the participants. During this session, they discussed the implications of (governments') COVID-19 (measures) for their schools, thereby exchanging strategies to cope. Principals hence anticipated the added value that can emanate from collective reflection with colleagues in case of highly uncertain and unforeseen events.

Table 5. Percentage of principals indicating (in the survey or interviews) to have gained from PLC participation in personal and/or practical terms.

\begin{tabular}{|c|c|c|c|}
\hline PLC Outcomes & $\begin{array}{l}\text { PLC } 1 \\
(\mathrm{n}=7)\end{array}$ & $\begin{array}{l}\text { PLC } 2 \\
(\mathrm{n}=5)\end{array}$ & $\begin{array}{l}\text { PLC } 3 \\
(\mathrm{n}=4)\end{array}$ \\
\hline \multicolumn{4}{|l|}{ Personal outcomes } \\
\hline Job enthusiasm & $0 \%$ & $0 \%$ & $0 \%$ \\
\hline Job satisfaction & $14 \%$ & $20 \%$ & $0 \%$ \\
\hline Self-efficacy & $29 \%$ & $40 \%$ & $50 \%$ \\
\hline Lowered feeling of professional isolation & $71 \%$ & $60 \%$ & $75 \%$ \\
\hline Feeling one can call upon others for help & $43 \%$ & $80 \%$ & $100 \%$ \\
\hline Feeling recognised and acknowledged & $71 \%$ & $20 \%$ & $50 \%$ \\
\hline The ability to ventilate frustrations and concerns & $86 \%$ & $100 \%$ & $75 \%$ \\
\hline \multicolumn{4}{|l|}{ Practical output } \\
\hline Inspiration & $71 \%$ & $60 \%$ & $75 \%$ \\
\hline $\begin{array}{l}\text { Knowledge about (sharing leadership, motivating personnel to collective } \\
\text { responsibility taking and/or) learning community functioning }\end{array}$ & $86 \%$ & $100 \%$ & $25 \%$ \\
\hline Concrete tools or material to take away and/or implement & $14 \%$ & $0 \%$ & $100 \%$ \\
\hline Strengthening of the ability to critically reflect on one's professional experiences & $71 \%$ & $100 \%$ & $100 \%$ \\
\hline Answers to specific policy challenges or questions they had at the start & $43 \%$ & $60 \%$ & $100 \%$ \\
\hline
\end{tabular}

\subsection{PLC 2-A Networked Community of Mainstream Secondary Eduction Principals}

\subsubsection{LPs and CES at Play and Interplay}

In Figure 4, panel (a) shows that while construction activities within PLC 2 seemingly increase, co-construction and constructive conflict remained constant. Meanwhile, panel (b) illustrates how the process coach, and pedagogical counsellor assuming a process coaching role, appeared less intensively involved than they were in PLC 1: $31 \%$ of construction activities, $39 \%$ of co-construction activities and $22 \%$ of constructive conflict activities observed were initiated by either two. 


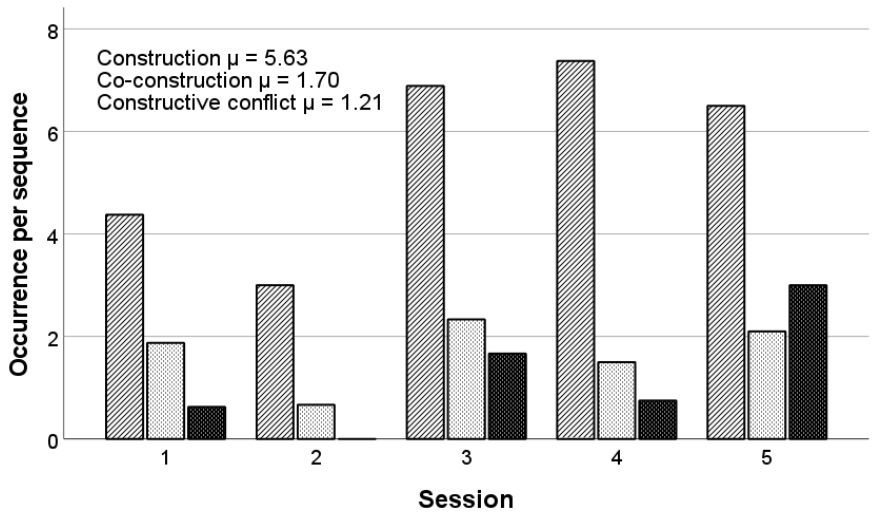

(a)

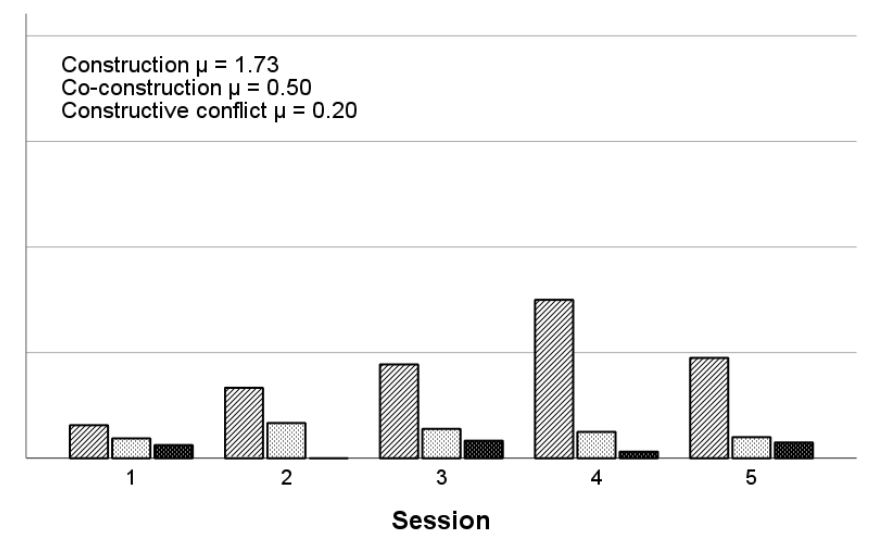

(b)

Figure 4. Evolution in the average occurrence of LPs per sequence (a) and LPs initiated specifically by both process coaches (b) within PLC 2. Legend of LPs represented: $\square=$ construction activities on average per sequence; $\mathbb{0}^{\circ}=$ co-construction activities on average per sequence; ${ }^{2}$ = constructive conflict activities on average per sequence. Note (1). The frequencies presented in Figure 4, panel (b) are based on the activity span of two process coaches. Note (2). ' $\mu$ ' expresses the average occurrence of each LP type over the course of five sessions.

Apart from the apparent rise in construction activities, Table 6 confirms the trends visualised by Figure 4 (panel A): No significant increases or decreases took place. Consequently, the overall activity span of the PLC did not significantly alter over the course of five sessions either.

Table 6. Occurrence pattern of LPs within PLC 2.

\begin{tabular}{ccccc}
\hline LP & $\boldsymbol{\lambda}$ & $\mathbf{t}(\mathbf{k} \rightarrow \mathbf{k})$ & $\begin{array}{c}\text { Observed Start } \\
\text { Value }\left(\mathbf{X}_{\text {start }}\right)\end{array}$ & $\begin{array}{c}\text { Probability }\left(\mathbf{X} \leq \mathbf{X}_{\text {start }}\right) \\
\sim \text { Pois }(\boldsymbol{\lambda})\end{array}$ \\
\hline Construction & 43 & $2^{\prime} 40^{\prime \prime}$ & 34 & 0.0940 \\
Co-construction & 13 & $8^{\prime} 51^{\prime \prime}$ & 14 & 0.6751 \\
Constructive conflict & 9 & $12^{\prime} 25^{\prime \prime}$ & 5 & 0.1157 \\
\hline Overall & 65 & $2^{\prime} 06^{\prime \prime}$ & 53 & 0.0735 \\
\hline
\end{tabular}

Note (1). $\lambda$-values were calculated based on an average session duration of 7,6 sequences or $115 \mathrm{~min}$. Note (2). $\mathrm{t}(\mathrm{k} \rightarrow \mathrm{k})$ pertains to the time between events $(\mathrm{k})$ expressed in minutes and seconds. Note (3). $\mathrm{P}\left(\mathrm{X} \leq \mathrm{X}_{\text {start }}\right)$ expresses a within PLC comparison under $\lambda$. Legend. ${ }^{*}=p<0.05,{ }^{* *}=p<0.01,{ }^{* * *}=p<0.001$.

Beyond this lack of noticeable trends is the fact that discussions within PLC 2 were frequently stalled by unbridled ventilation of frustrations about legislative updates and/or limitations. This happened without the principals ever actively taking these sources of concern to hand by collectively developing concrete answers or strategies to cope-to the great frustration of some:

[Ventilating frustration] is all very well but we can't change those things. You can want something and keep on wanting the same thing. And, a lot of [PLC] time was spend on ventilating frustrations. I found that very annoying-because the answer is 'no' and will always remain 'no' (principal 5-female-2 years of experience).

Of course, these lamentations took away time from the main objective: Learning from and improving each other's practice through an in-depth discussion of why certain practices work while others do not and how to avoid their pitfalls. Moreover, when principals came to sharing good practices, they often restricted themselves to 'long-drawnout stories' (cf. principal 4-female-11 years of experience) based on limited detailed PowerPoint presentations. Concrete materials (such as policy plans or assessment tools) were hardly exchanged, let alone discussed in-depth with an improvement aim. Or, as a member accurately described: 
It was always just intervision: Talking and bringing things up. I thought, however, the objective was to collectively design material that could find a real implementation in schools (pedagogical counsellor 3).

Behind these figures is also a continuous struggle and concomitant effort by both the process coach and pedagogical counsellor to redirect the course of PLC discussions and to stimulate principals to co-construction. For this reason, and in comparison to PLC 1 , more time was deliberately spent on theoretical intermezzos and short recaps. These functioned as a cold reset of PLC operations: A renewal of principals' attention for the PLC's objectives. An effort that-as shown by Table 6-never succeeded. A triangulation of the observation and interview accounts with the questionnaires singled out four-mutually reinforcing-explanations for principals limited engagement. Each emerging from the group developmental characteristics of this PLC. The first reason was already touched upon in the case description: The lack of a shared understanding of PLC objectives stemming from the fact participants brought very different expectations to the table. As PLC 2's proceedings landed on a common denominator, it left all members somewhat disappointed.

A second reason entails clashing characters among both the principals and pedagogical counsellors. Interview accounts tell how these personal sentiments left some passive spectators of the PLCs activities, demotivated to open up their private practice to fellow community members and, unwilling to invest too much of their precious time as others seemingly did not either. A finding that also finds confirmation in Table 4 (cf. supra) which entails the lowest social cohesion score (with the highest standard deviation) for PLC 2. Albeit, group psychological safety is assessed remarkably high. An explanation for this paradox might be:

I believe [the PLC] to be a very safe environment in the sense that we only talked about good practices. If we were to discuss things that go awry and require a solution than it would have been entirely different [ . . ] If everyone only comes with something they are good at, safety in itself is less important because you do not have to show your vulnerable side (principal 5-female-2 years of experience).

Also from Table 4 (cf. supra), a negatively perceived task cohesion appears as a third reason. As task cohesion pertains to the profound belief that collaboration within the PLC can render results that are beneficial to each' professional practice and are thence worth one's time, negative perceptions thereon can keep principals from truly investing. This, of course, hampers LPs. Given that principals were unacquainted, these figures should not come as a surprise, however: Participants are simply unaware of each other's abilities and the extent to which these can function as a resource for information, ideas and useful feedback. A PLC among unacquainted principals thence profits from elaborate introductions and teambuilding in order to establish these shared mental models and perceptions of task cohesion.

A final and fourth reason can be described as inadequate steering of PLC activities. Multiple references were made to organisational elements that participants missed, yet might have allowed more structure and eventually focus (e.g., a fixed meeting calendar; a structured agenda including minutes from the last meeting by means of recaps; preparatory assignments and/or a frequent reminder to share documents and where to share them to). As a concrete example, principals recalled how a promising tool for policy plans and school innovation (i.e., so-called 'project card') was introduced in one session yet, lost out of sight the next:

At a certain point in time, the project card was introduced and for which I had some ideas but it has never been developed thereafter. A shame, I think as I had a lot of questions about [this tool] and am still searching for an answer. I did not receive feedback nor insight in how colleagues filled out this document. A pity because I truly deem this an interesting instrument (principal 6-female12 years of experience). 
Others confirmed her perception in stating:

Learning is more than simply acquiring information at a certain point in time. To learn, information needs to be processed (principal 4-female-11 years of experience).

Exact processing, as felt by all PLC members, became lost in the multitude and incoherence of the personal stories and concerns shared. It thus seems that several group developmental factors kept individually enthused principals from active engagement on a group level. This reflected in a relatively low attendance rate per session, again, hampering adequate group development and affecting principals' enthusiasm to partake for the worse: The frequently changing group composition caused a lot of repetition to take place in order to keep principals who missed out on a session in the loop. A PLC comprised of unacquainted principals would thence benefit from a high and constant attendance rate to avoid seemingly unnecessary repetition.

In sum, and unlike in PLC 1, the essential building blocks to move from sharing to co-construction and constructive conflict were never truly present within PLC 2.

\subsubsection{Process Guiding}

What part did the process coach and pedagogical counsellors play in the preceding conclusion? Figure 5 shows how the process coach' and pedagogical counsellor's efforts to keep the group focussed on PLC objectives were not quite represented in the role behaviour figures. On average, a coordinating role was observed most frequently: $65 \%$ of sequences contained one or more coordinating interventions compared to $57 \%$ and $51 \%$ for respectively coaching and expert interventions.

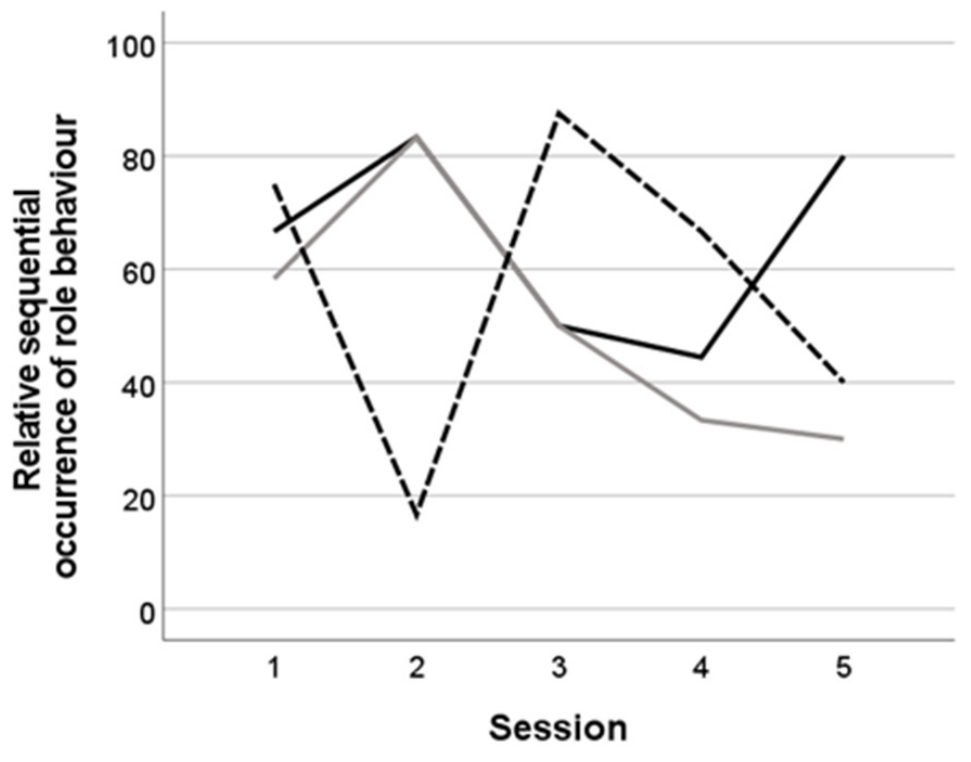

Figure 5. Evolution in the process coaches' role behaviour over sessions within PLC 2. Legend. Black line $=$ coordinating role; grey line $=$ expert role; dotted line $=$ coaching role. Note. These figures are based on the activity span of two observed process coaches.

All percentages fell behind those of PLC 1. This is remarkable given a tighter steeringand thus more frequent occurrence of all roles-might not only have been desirable to keep PLC 2's activities on track but was also clearly expected by the participants. Although principals were satisfied by the expert interpretation, they united in their conviction PLC guidance would have benefited from (a) a tighter grip and more intensive stimulation towards co-creation and, (b) a more challenging line of questioning about school practices. In sum, a stronger interpretation of the coordinating and coaching roles. Because of this discrepancy between observed, perceived and expected role behaviour, the process coach 
and pedagogical counsellor were also found to have a clear-yet perhaps unwittingimpact on the PLC's group developmental features:

Each time [principal 4 told] the same story. I think I have heard it ten times over the past school year! It is of no values that someone brings things up over and over again. The coach and counsellor who lead the community should be more alert to that $[\ldots]$ there should be more feedback from them towards members and their functioning within the group [ ... ] For us, it is difficult to address a fellow principal (principal 5-female-2 years of experience).

From the interviews, we might also conclude that principals relied (too) heavily on both the process coach and pedagogical counsellor to adjust proceedings whilst rarely critically assessing their own part:

At the beginning I really enjoyed working with [the process coach and pedagogical counsellor]: they do know a lot and I believe they can support you. But towards the end that all disintegrated a bit: there was more repetition and less new input. It felt like we were going round in circles (principal 6-female12 years of experience).

A PLC might, therefore, benefit from role clarity when it comes to its leadership (e.g., assigning a pedagogical counsellor a coordinating role while restricting the process coach' role to coaching from an expert position). That way, principals know beforehand from whom to expect which intervention and when to take their own responsibility.

\subsubsection{To Participate or Not to Participate: PLC Output and Outcomes}

Table 5 (cf. supra) indicates that despite all the difficulties to get LPs within PLC 2 going, principals did not consider the participation a waste of their precious time. Although principals were very vocal about the inadequacy of practical output (in terms of concrete implementable materials and answers to policy-specific questions), they all did confirm to have broadened their knowledge base on learning community functioning and/or sharing leadership. A first step in the PLCs underlying objective consequently seems fulfilled, albeit these new insights were rarely processed let alone acted upon through tangible application or enhancement in one of the schools. Furthermore, although often limited in detail, more than half of the principals indicated to have acquired inspiration from fellow principals' good practices and/or the process coaches' input.

Moreover, Table 5 illustrates that notwithstanding the small frustrations and/or individual disappointments, bringing principals together on a regular basis in itself seems enough to allow for beneficial personal outcomes that can provide mental support and ease perceived professional grievances:

It is also about supporting each other. We all do the same job. We all search for a moment to ventilate and listen how [fellow principals] cope. To me, those social and mental aspects are important too. And, those [the PLC] did include (principal 2-male-6 years of experience).

Both findings reflect in the rather highly perceived group effectiveness figures presented in Table 4 (cf. supra).

\subsection{PLC 3-A Networked Community of Well-Acquinted Secondary Education Principals}

\subsubsection{LPs and CES at Play and Interplay}

While construction activities appeared at a similar rate throughout four sessions, both co-construction and constructive conflict processes occurred seemingly more often as time progressed (cf. Figure 6, panel (a)). A finding that finds confirmation in Table 7 as a comparison of the observed start values for each LPs category to the category's average, twice rendered a significant result (or chance estimation) for the latter two. Looking at LPs in overall terms, the rise in their occurrence did not reach statistical significance. Albeit, 
PLC 3 registered both the highest and most diversified number of LPs (averagely speaking) of all three PLCs (cf. Tables 3, 6 and 7).

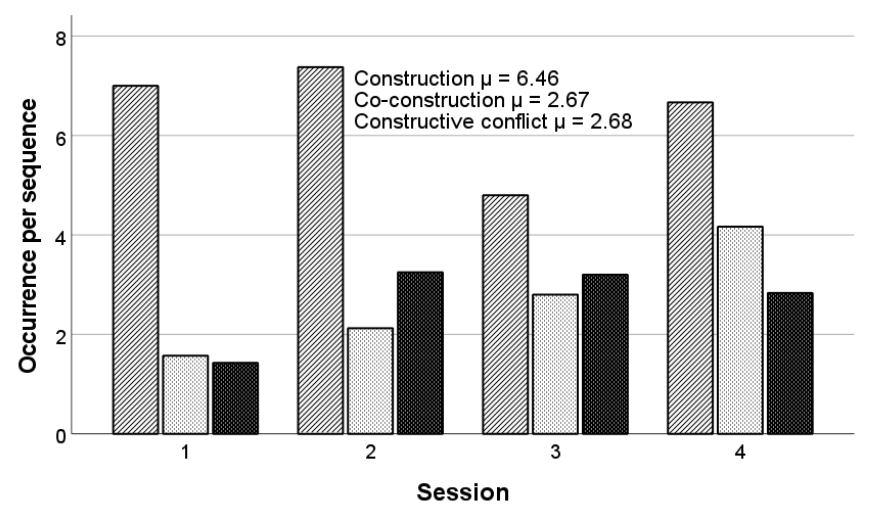

(a)

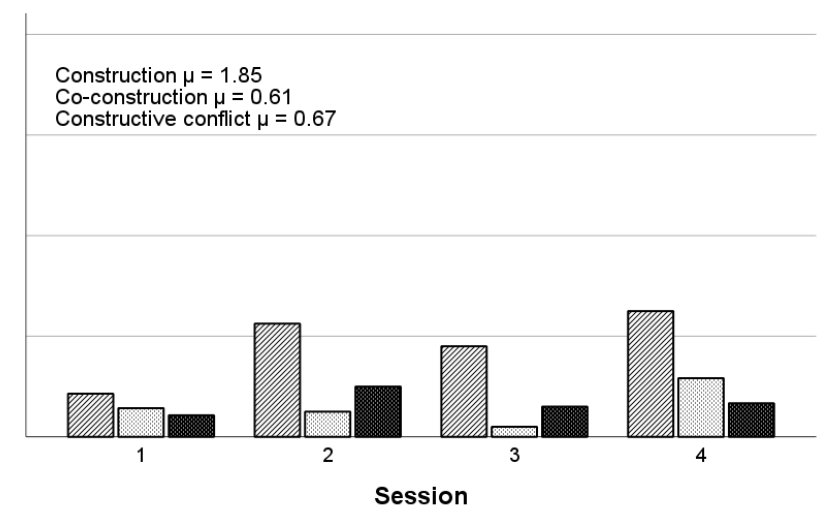

(b)

Figure 6. Evolution in the average occurrence of LPs per sequence (a) and LPs initiated specifically by the process coach (b) within PLC 3. Legend of LPs represented: $\square=$ construction activities on average per sequence; $\mathbb{Z}^{\circ}$ co-construction activities on average per sequence; = constructive conflict activities on average per sequence. Note (1). The frequencies presented in Figure 6, panel (b) are based on the activity span of one process coach. Note (2). ' $\mu$ ' expresses the average occurrence of each LP type over the course of four sessions.

Table 7. Occurrence pattern of LPs within PLC 3.

\begin{tabular}{ccccc}
\hline LP & $\boldsymbol{\lambda}$ & $\mathbf{t}(\mathbf{k} \rightarrow \mathbf{k})$ & $\begin{array}{c}\text { Observed Start } \\
\text { Value }\left(\mathbf{X}_{\text {start }}\right)\end{array}$ & $\begin{array}{c}\text { Probability }\left(\mathbf{X} \leq \mathbf{X}_{\text {start }}\right) \\
\sim \text { Pois }(\boldsymbol{\lambda})\end{array}$ \\
\hline $\begin{array}{c}\text { Construction } \\
\text { Co-construction }\end{array}$ & 50 & $2^{\prime} 19^{\prime \prime}$ & 54 & 0.7423 \\
Constructive conflict & 20 & $5^{\prime} 38^{\prime \prime}$ & 12 & $0.0390^{*}$ \\
\hline Overall & 21 & $5^{\prime} 36^{\prime \prime}$ & 11 & $0.0129^{*}$ \\
\hline
\end{tabular}

Note (1). $\lambda$-values were calculated based on an average session duration of 7,6 sequences or $115 \mathrm{~min}$. Note (2). $\mathrm{t}(\mathrm{k} \rightarrow \mathrm{k})$ pertains to the time between events $(\mathrm{k})$ expressed in minutes and seconds. Note (3). $\mathrm{P}(\mathrm{X} \leq \mathrm{X}$ start $)$ expresses a within PLC comparison under $\lambda$. Legend. ${ }^{*}=p<0.05,{ }^{* *}=p<0.01,{ }^{* * *}=p<0.001$.

Within PLC 3's activity, panel (b) shows the process coach to have acted as a primus inter pares. With an average of $26 \%$ initiated LPs, her contribution approximated that of other (active) group members. She never did outshine the others as her contributions to, respectively, construction, co-construction and constructive conflict efforts equalled $29 \%$, $24 \%$ and $26 \%$.

Knowing principals within PLC 3 to be the most (evenly) active and least restricted to mainly construction activities, how then did work within the community proceed? The group commenced by defining its objective. Which difficulties did group members individually perceive about the inspectorate's new framework to assess their quality of education by? From the tour de table arose the need for a workable tool to store, visualise, maintain and communicate quality (and concomitant policy) requirements. In order to design a tool that met all expectations, community members deemed it desirable to draft an overview document first in which all background documents were summarised and the frameworks' quality standards were provided with explanatory notes where needed. From the very first session, principals proceeded with focus as elements that were unclear were marked and, perspectives and ideas were exchanged on how to read these and where to find additional information. Principals, moreover, agreed to homework as some were to continue with parts of the overview document while others assessed the digital possibilities available to the group for tool development. This functional task division 
led to (a) a comprehensive daft of the overview document and (b) two elaborated tool suggestions. All of which were discussed in the fourth and final session.

It should be noted that throughout four sessions, the groups' objective was also gradually refined as deviating opinions were voiced on how to accomplish the desired tool. Disagreement was settled through intuiting back-and-forth discussions in which all principals partook.

Why was PLC 3 the only community truly able to convene principals for co-creation? Apart from the narrowly defined objective endorsed by all group members, three other factors seem to have contributed. For one, PLC 3 was perceived as the safest of all PLCs (cf. Table 4). Not only did principals feel at ease revealing their learning needs, but they also felt self-confident enough to voice their perspective on the topic at hand and share documents that might not have been entirely finished.

[It was] very safe to declare inexperience or put questions forward. Certainly. Everyone dared to show his or her vulnerable side and describe what he or she struggles with (principal/coach 16-female-4 years of experience).

Something the process coach was believed to have a substantial contribution to:

Within our team [the process coach] is seen as someone with experience. Someone that runs her school effectively. She is easily approachable, which is important and partly created safety [within the group] (principal 15-female-3 years of experience).

Merit seems to emanate from opting for an internal process coach over an external one for the former proves better equipped to show a vulnerability that other principals can relate to. Vulnerability can provide them with the necessary confidence to do the same, inspiring LPs in turn. As can be seen in both Figure 6, panel (a) and Table 7, these findings translate in all types of LPs occurring early on and with a relatively high frequency.

A second reason lies in the fact that neither the process coach nor the pedagogical counsellor transcended PLC activity. The former merely steered PLC processes (cf. infra) whilst the latter only intervened when asked for additional perspective. None of them held the answer to the group's collective search for a convenient tool. So if one wanted the PLC to succeed - which all of them did, it was of no use to adopt a wait-and-see attitude:

When we divided tasks, I did notice that in being assigned a certain part, everyone had the sense of honour and duty to actually complete. [ ... ] I thought everyone to have completed the task well. That is again prove that making clear arrangements about tasks and deadlines works (principal/coach 16-female4 years of experience).

This so-called 'sense of honour and duty' is of course closely connected to the notion of task cohesion-or the profound belief one can individually benefit from the group's effort and success. This third and final explanatory factor was perceived remarkably higher within PLC 3 than within the other two PLCs (cf. Table 4):

I mainly take way from [the PLC] that I was not alone in [dealing with the new framework]. Often I think to myself [about legislative updates]: "I do not understand at all. I do not even know where to start". Through the discussions I felt at ease: "Together we'll work things out" (principal 15-female-3 years of experience).

Given principals (including the internal process coach) and the pedagogical counsellor only partook in the post hoc part of this research design, it is nonetheless impossible to tell whether their appraisal preceded PLC gatherings or emerged as a consequence thereof. After all, being well-acquainted allows gauging fellow principals' potential value to one's own practice more correctly. Meanwhile, four sessions appear a very limited timeframe for task cohesion sentiments to develop. A combination of both, therefore, seems most likely. Finally, it requires special mentioning that PLC 3, contrary to PLC 2, demonstrated how a mixed community composition with experienced and in-experienced principals 
implied no decisive difference to the community's outcomes and output. That is, as long as all members pursued the same objective and held comparable expectations. While an inexperienced principal (i.e., principal 14-male-1 year of experience) related on how he appreciated the knowhow that had been shared in response to his questions, a more experienced principal reported:

[The more experienced principals] can really contribute while the less experienced principals pose exploratory questions. By formulating an answer [to those questions] I manage to put things straight again in my head (principal/coach 16 - female -4 years of experience).

The citation refers to a win-win situation that was never perceived as an inconvenient deceleration of PLC activity. Instead, it allowed the reflection needed to continue with a co-construction that benefitted all.

\subsubsection{Process Guiding}

Given PLC 3's objective differed from that of the two other PLCs, so did the process coach's role. Figure 7 thence confirms the process coach never had to adopt an expert role as this PLC did not share the other PLCs' underlying objective of imparting knowledge about distributing leadership and learning community functioning. Instead, she mainly took coordinating actions.

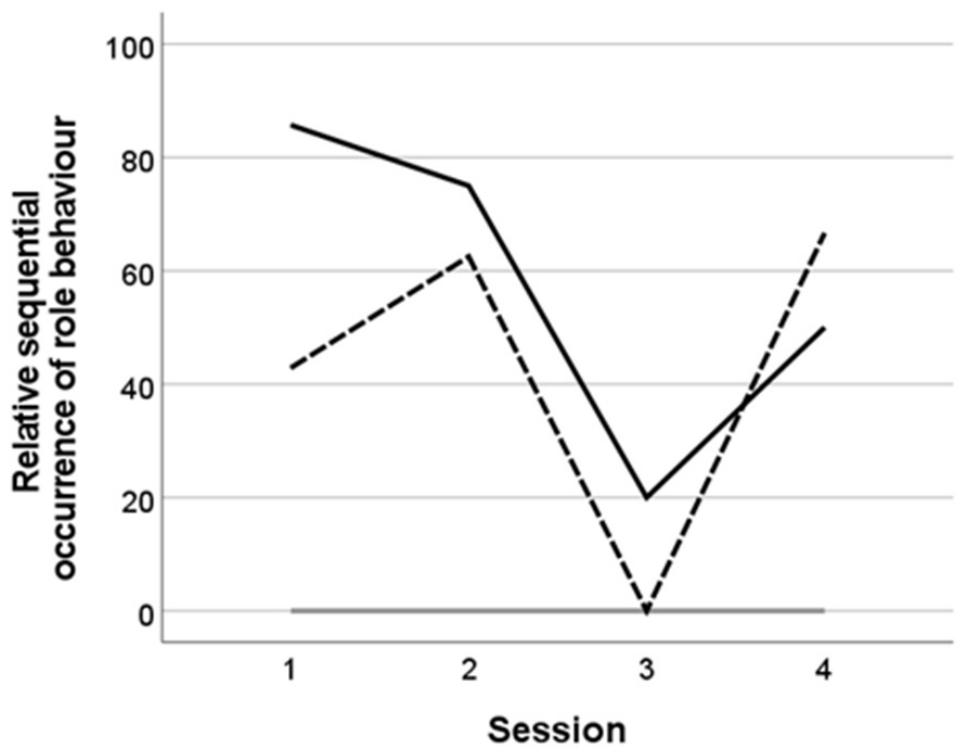

Figure 7. Evolution in the process coaches' role behaviour over sessions within PLC 3. Legend. Black line $=$ coordinating role; grey line $=$ expert role; dotted line $=$ coaching role. Note. These figures are based on the activity span of one observed process coach.

From the interviews, it became clear that this coordinating process guiding was not only the role group members truly expected from their process coach but also perceived her highly effective in. As PLC 3 proves the first case in which the process coach's observed, perceived and expected role behaviour aligned, her role interpretation never met with criticism in the interviews-except for self-criticism:

I try to make the learning community challenging to myself and that is of course a pitfall. When others remain silent, I tend towards filling in this silence by thinking out loud. Which is not always good (principal/coach 16-female4 years of experience).

This was something the other group members did not seem to have noticed and which was even appreciated by the less experienced principals given her brainstorms also trig- 
gered their thinking processes. With a mere four sessions observed, this study was however unable to discern meaningful alterations or shifts in the process coach's role behaviour.

\subsubsection{To Participate or Not to Participate: PLC Output and Outcomes}

Despite the limited amount of sessions, PLC 3 proceeded as very hands-on. According to Table 5 (cf. supra), practical output extends beyond the earlier-on described explanatory document and overview tools which principals respectively drafted and gave impulse to. All principals signified to have acquired insight into the new quality framework and the way in which its quality standards should be read. Both colleagues' divergent perspectives and the mutual commitment to process a part of the policy documents about the framework each, appeared the most useful aid to this knowledge acquisition. In this regard, nearly all principals were found to have received an answer to policy questions they had about the Inspectorate 2.0.

These practical outcomes do, however, not entirely reflect in the group effectiveness figures presented in Table 4 (cf. supra). The dispersion of the measure reveals how group members adopted a critical attitude towards the PLC's functioning which rendered some not completely satisfied with its progress:

At times, we lost our result-oriented focus because we could not get the objective straight. So yes, there is little output at the moment even though we have a highly clarifying document. Of course, we were not able to conclude the trajectory [due to COVID-19] (principal/coach 16-female-4 years of experience).

Voiced discontent was nonetheless always accompanied by a belief in the group's ability to deliver practical output-or provide its members with a useful base to do so themselves:

[... ] I hope we can continue during the next school year because, despite the limited output, [the PLC] involved very relevant things: I do have the impression I grew, or know more than I did without the PLC (ibidem).

As to social outcomes, PLC 3 was again seemingly more effective than were PLCs 1 and 2. Albeit, different types of personal outcomes received reference-or, met with scepticism (e.g., a PLC was explicitly mentioned not to be the proper nor desired platform to ventilate frustration). PLC 3 principals attached most importance to fellow principals ${ }^{\prime}$ ability to boost one's own self-efficacy and provide reassurance that one was not alone in coping with policy challenges. The following quote expresses such outcomes:

When I heard from other schools-and principal 16 was always very open to sharing her school's policy documents - that they still had topics indicated red too, I thought that it wasn't all that bad. That added greatly to my well-being: thinking I was miles behind while it turned out to be only a few feet (principal 14-male-1 year of experience).

Table 8 provides the reader with a summative overview of the main elements discussed and compared per case. 
Table 8. Summative overview of the main elements/variables discussed per case.

\begin{tabular}{|c|c|c|c|}
\hline Variables & PLC 1 & PLC 2 & PLC 3 \\
\hline \multicolumn{4}{|l|}{ Team learning processes } \\
\hline Construction & $\uparrow$ & $=$ & $=$ \\
\hline Co-construction & $=$ & $=$ & $\uparrow$ \\
\hline Constructive conflict & $=$ & $=$ & $\uparrow$ \\
\hline \multicolumn{4}{|l|}{ Process coach } \\
\hline Ascribed construction activities & $28 \%$ & $31 \%$ & $29 \%$ \\
\hline \multicolumn{4}{|l|}{ Ascribed co-construction activities } \\
\hline \multicolumn{4}{|l|}{$\begin{array}{l}\text { Ascribed constructive } \\
\text { conflict activities }\end{array}$} \\
\hline \multirow{2}{*}{\multicolumn{4}{|c|}{$\begin{array}{l}\text { Overall activity level TLPs } \\
\text { Observed role behaviour }\end{array}$}} \\
\hline & Coach & Coordinator & Coordinator \\
\hline \multicolumn{4}{|l|}{ Expected role behaviour } \\
\hline \multicolumn{4}{|l|}{$\begin{array}{l}\text { Perceived role behaviour } \\
\text { CES }\end{array}$} \\
\hline \multicolumn{4}{|l|}{ Group psychological safety } \\
\hline Social cohesion & Fair & Fair & Rather good \\
\hline Task cohesion & Adequate & Rather poor & Fair \\
\hline Shared conception of & Adequate & Adequate & Rather good \\
\hline \multirow{2}{*}{\multicolumn{4}{|c|}{$\begin{array}{l}\text { Group effectiveness } \\
\text { Main outcomes and output }\end{array}$}} \\
\hline & & & \\
\hline Personal level & $\begin{array}{l}\text { Professional isolation } \downarrow \\
\text { Ability to ventilate frustration } \uparrow\end{array}$ & $\begin{array}{l}\text { Feeling one can call for help } \uparrow \\
\text { Ability to ventilate frustration } \uparrow\end{array}$ & $\begin{array}{l}\text { Knowing who to call for help } \uparrow \\
\text { Self-efficacy and confidence } \uparrow\end{array}$ \\
\hline \multirow{2}{*}{ Practical level } & Acquisition of knowledge & Acquisition of knowledge & Tangible document and tools \\
\hline & Acquisition of inspiration & Acquisition of inspiration & Answers to policy questions \\
\hline
\end{tabular}

Note (1). The numeric values corresponding to CES composite measures presented in Table 4, were given a categoric value in this overview. Hence, labels correspond to the following values: $-2=$ non-existent; $-1.5=$ very poor; $-1=$ poor; $0.5=$ rather poor; $0=$ adequate; $0.5=$ fair; $1=$ rather good; 1.5 = good; $2=$ excellent. Note $(2) . ~ ' \uparrow$ ' signifies an increase, ' $\downarrow$ ' a decrease and ' $=$ ' a constant.

\section{Discussion}

In this case-based research, three PLCs of secondary education principals-based on two different set-ups-were found to follow a unique development pattern each. These patterns rendered a variety of practical outputs and personal outcomes. All of which will be discussed throughout this section and related to existing research.

\subsection{PLC Output and Outcomes}

Corroborating findings from other studies in the field $[7,40,78,86]$, this study found that bringing principals together on a regular basis in itself seems enough to allow for beneficial personal outcomes that can provide mental support and ease professional grievances. Principal PLCs—and peer counselling more in general-have the potential to add to one's professional well-being by reducing a feeling of professional isolation which school principals often report [8] and by giving opportunities to ventilate both frustrations and concerns about school challenges, even if interactions are not that much structured or focussed on a specific policy question [87]. Furthermore, we found principal PLCs to contribute to the individual professional learning of school leaders. Yet, the extent to which is dependent on the degree, nature and quality of the practical outcomes (e.g., such as the materials exchanged). Moreover, a lot of informal learning can originate from gathering with colleagues $[88,89]$. Nearly all principals confirmed that the support or inspiration they received from peers had the potential to trigger a critical individual reflection; which, in itself, has the potential to motivate a principal in acquiring even more meaningful learning experiences as (s)he gradually becomes more aware of his or her points for professional improvement [18]. Hence, Leithwood and Azah [90] rightfully describe participation in leader networks as 'a key strategy for school leadership development'.

These findings help us explain why participating principals appeared satisfied with the PLC process even if it did not render transfer(able) effects [91]. Of course, as Huber [20] described: 'Learning transfer' is only one of the possible criteria to assess the added value of CPL. Furthermore, from the case comparison differences arose in the extent to which PLCs can provide principals with concrete support by means of jointly developed material or well-thought-out approaches to the problem situation or policy issue at hand. These differences between our PLCs appeared associated with differences in group development, the occurrence pattern of LPs and process coaching behaviour. 


\subsection{Conditions for Succesful Principal PLCs}

Considering how LPs emerged and evolved over time, we noticed how the construction type of LPs occurred most frequently in each of our cases. Principals articulated their individual experiences with the central theme, shared grievances and listened carefully to group members. Considerable differences existed, however, in (a) the quality and quantity of construction activities, (b) whether these were initiated by either the principals or the process coach(es) and (c) the extent to which these led to co-construction.

At times when the discussions were clearly focussed on the PLCs' objective(s), the degree of co-construction activities increased: Principals started to add, refine, build on or modify the individual input from the previous construction phase. In turn, these collaborative construction efforts led to the emergence of new ideas and, a deepened or deepening insight into some central concepts. Whereas co-construction LPs occurred often and were of good quality within PLC 3, principals within PLCs 1 and 2 had more difficulty elevating discussions to a co-constructive level. In these PLCs, co-construction often came to an early close when discussions had to become more concrete and critically applied to the principals' own school context. In spite of a highly perceived group psychological safety, some principals clearly perceived this step as threatening. It should nonetheless be noted that even without further co-construction, the chance to construct in itself was already regarded as positive by most of those principals.

Building on the previous point, the incorporation of divergent viewpoints through critical yet constructive reflection, debate and feedback was nearly non-existent in PLCs 1 and 2. In those, principals seemed to avoid being too critical of their peers as this could affect the positive group atmosphere and one's reputation within the community. PLC 3 principals showed less reservations in this regard. The fact that they were well-acquainted also made it easier to be constructively critical of their colleagues' ideas or experiences. We are aware that PLC 3 also benefited from the fact that the topic discussed was detached from a specific school context (i.e., as it applied to each school represented around the table in exactly the same way). Given constructive conflict was rather related to a generic product instead of a colleague's personal professional experiences or school context, principals had an easier time providing each other feedback.

In line with other research in the field $[85,92,93]$, this study found three organisational conditions of notable importance in the occurrence of LPs as described above. One, a clear, delineated and realistic objective which all group members agree and commit to at the start of a PLC trajectory was found essential. Conflicting expectations and ambiguity about the PLCs objectives were found to cause dissatisfaction with the PLC process, outcomes and output. On the contrary, agreed objectives had the ability to motivate principals towards a desired end as they were well aware of the personal professional advantage(s) this implied.

Two, agreed goals require apt orientation: Adequate steering and preparation of PLC activities proved indispensable to achieve the group's objective(s). In PLC 3, principals agreed to homework between sessions and allowed the process coach to closely monitor its progress. Both the functional task division and strong coordinating interpretation by the process coach, allowed PLC 3 to make more progress in terms of concrete output than PLCs 1 and 2. In the latter two PLCs, principals were often asked by the process coaches to share their relevant material so that these could be discussed during the next session. Yet, these requests were seldom answered by the participants, nor followed up as conscientiously by the process coaches as they were in PLC 3 . Arrangements, perceived by the principals, had too much of a noncommittal character. Principals within PLCs 1 and 2, furthermore, lacked coordination in the sense of a clear meeting agenda, minutes from past meetings and small reflection exercises to prepare them for the next meeting and refresh their memory of what happened in the previous one. Research by Aas and Paulsen [77] suggest that considerable value can emanate from such reflexive preparatory assignments and principals being urged more firmly to share material.

Three, PLC participation should be logically embedded in participants' daily routines and activities. This implies (a) the ability of a PLC to accommodate a principal's pre- 
existing needs by providing practicable answers, tools or solutions and, (b) a structured integration of the PLC in his or her professional schedule (e.g., a predefined and agreed meeting calendar around which participants can plan well in advance, such as applicable in PLC 3, instead of the ad hoc arrangements which were typical to PLCs 1 and 2). Prenger and colleagues [27] described logical embeddedness as having a particularly large effect on member's estimation of knowledge, skills and attitudes acquired on the one hand and their satisfaction with the PLC product and process on the other. A relation, this study confirmed and found to be mediated by LPs: Without perceiving logical embeddedness, principals were inclined to adopt a wait-and-see attitude which hindered the build-up in LPs and consequently, the output and outcomes those can lead to. Several other authors too, described logic embeddedness as a vital criterium to assess the effectiveness of CPL initiatives $[18,19,94]$.

Finally, it requires special mentioning that PLCs 1 and 3 demonstrated how a mixed community composition with experienced and inexperienced principals implied no decisive difference to the community's outcomes and output. As long as all members pursued the same objective(s) and held comparable expectations, varying experience levels were not perceived as an inconvenient deceleration of PLC activity. This finding parallels Stewarts' [95] results, as he found group heterogeneity and performance to correlate near zero.

In comparing our three cases, we found the frequency with which certain types of LPs occurred clearly dependent on group dynamics and the emergence or presence of positive group affects (i.e., CES). First, the perception of the group's objective(s) as being shared and agreed, led principals to trust in other members' commitment to the PLC. Of course, seeing others commit, makes one commit too. Principals' engagement to their PLC could be strengthened further by decent cohesion levels. While social cohesion motivated members to help each other succeed and overcome their learning question(s) and/or need(s); task cohesion allowed principals to experience pleasure from completing a joint objective. Given each of these CES motivated principals to a more active engagement, they also caused more construction and co-construction to take place. Second, group psychological safety was found to influence (a) the information principals shared (i.e., both in terms of quality and quantity) and, (b) if and how they reacted to their peers' shared experiences. The more psychologically safe one felt within the group, the less reservations one seemed to have in being constructively critical towards fellow members' contributions, ideas or opinions. Overall, only within our third case-in which principals were wellacquainted and some favourable CES such as group psychological safety were present from the start—did principals manage to regularly enter into constructive conflict activities.

Our findings perfectly connect to Vangrieken, Dochy and Raes' [33] concept of 'team entitativity' and assertions about its impact on LPs. We too observed that the more a group of PLC members functioned as a team-characterised by a well-perceived group psychological safety, social and task cohesion and a shared perception about the group's objectives - the more numerous and diverse LPs were. This, in turn, rendered principals more satisfied with the PLC's process. Principals were found to report more personal outcomes and practical output too. Hence, adequate group development to nurture each of the CES proves an indispensable feature of efficacious networked PLCs among school principals.

Although we recommend the organisers of future networked PLCs for principal CPL to carefully consider group development, it remains to be seen whether this can ever grow into full stature among unacquainted to fairly acquainted principals. For, whereas a clear line of communication can aid members' perception that everyone agrees on a narrowly defined objective the group is to pursue, all other parts of group development are harder to come by as time to deliberately spend on those will always be scarce. We noticed that as our principals operate in a demanding environment $[2,8]$ in which a multitude of small and ad hoc problems require a lot of their precious professional time [96], they were only able to meet at a relatively low frequency with fluctuating attendance rates. Exactly those frequent changes in group composition strongly hampered group development, definitely within 
the entirely unacquainted group: Members had to repeatedly introduce themselves, their school context and learning questions. These circumstances made it unlikely for positive group dynamic features to be easily established. Without those, even after the passing of time and a certain amount of sessions, principals might still be dubious about the benefits of PLC participation to his or her professional practice.

Building on recent research by Aas and Paulsen [77] and recommendations from Huber $[18,20]$, we suggest adopting an integrated approach characterised by a diversification of learning methods used within CPL set-ups similar to those of PLCs 1 and 2 (i.e., convening fairly acquainted to unacquainted principals around complex and sensitive topics). Such an approach can encourage an individual (learning) profit and the occurrence of LPs in a PLC in spite of mediocre CES levels. PLC engagement can for example be supplemented with an intensive one-on-one coaching trajectory at the school floor. What has been thought, learned or discussed within the community can, therefore, find refinement in practice. A process that generates new experiences and insights that can, in turn, be brought back to the community. A circle of continuous (self)reflection and, knowledge and experience acquisition is hence set in motion. It is reasonable to assume that such a set-up can also aid principals in translating practical PLC output (i.e., minimally comprising of inspiration or loosely-connected ideas) into personal actions and/or school policy-ideally leading to meaningful leadership and/or school improvement [77]. The question about how — and if [97] — we can guarantee inspiration, knowledge and/or co-created material or tools to find its way outside a PLC and into secondary schools, however, still requires further clarification. Additional research guided by learning transfer literature can yield more insight.

\subsection{The Role of the Process Coach}

First, we found that different PLC set-ups led to different process coaching behaviour. PLCs 1 and 2 commenced by introducing external expertise to accustom principals with the concepts of distributed leadership and learning community functioning in order to get PLC activities started. Early on, however, it became clear that the central objective of inspiring school leaders to distributed leadership proved too demanding for the principals involved as it involved a very broad and complex theme that could and had to be filled out differently for each principal in his or her school. For this reason, the process coaches had to frequently revisit the role of expert.

As apparent as the expert interpretation, were actions by the process coaches that connected to a coaching interpretation. They encouraged principals to share their distributed leadership examples and experiences, probed for further details or clarification and, posed questions to incite collective and individual reflection processes. Although inspiring to nearly all principals, we also found that these actions made principals within PLC 2 overly reliant on the process coaches' interventions. Whereas principals in PLC 1 made use of the encouragements and gradually started to initiate significantly more construction activities, their counterparts in PLC 2 never truly did.

In PLC 3, the process coach never had to adopt an expert role as there seemed to be sufficient expertise in the group. Instead, the process coach mainly took coordinating actions. Due to the limited complexity and neat delineation of the group's objective, those actions were easier to focus on. Unlike the process coaches within PLCs 1 and 2, she never had to search for discussion leads to keep the conversation from lapsing into a standstill, actively encourage peers to meaningful contributions or prevent them from drifting off topic.

In none of our three cases did the roles that the process coach(es) adopted, alter considerably over time. As described above, on average, a coordinating interpretation was pursued most often. As adequate structuring and steering of PLC meetings proved of paramount importance throughout the sessions, this role was either the one to meet with most criticism (in PLCs 1 and 2) or compliments (in PLC 3). What did alter in PLC 1, however, were the process coach(es)' contribution to the LPs. As the group started to 
pursue its objective in an effective and efficient way, we witnessed a decline in times that the process coaches' had to intervene with a construction, co-construction or constructive conflict action-a positive evolution that was never apparent in PLC 2. Here, process coaches had to continue their efforts to keep discussions going by discussing concepts and providing examples and/or reflections.

Second, we found principals within PLC 3, which was led by an internal process coach, to be more satisfied with both the process and end product than were principals within both PLCs 1 and 2. We also observed more practicable output within PLC 3 than we did within the other two PLCs. These findings, nonetheless, might have been mediated by the PLCs goal complexity.

Third, and building on the second finding, we found that an alignment in observed, expected and perceived role behaviour by the process coach added to principals' overall satisfaction with the PLC process and output. A PLC, therefore, seems to benefit from clarity about the process coach' or process coaches' role. A clear delineation at the start might for instance assign one process coach a clear coordinating role while restricting that of another to coaching from an expert position or being more strict on having tasks performed between sessions. That way, principals know beforehand from whom to expect which intervention and when to take their own responsibility.

Our data pointed out the importance of a process coach - either internally or externallyadopting a coordinating role. A chairperson or group facilitator who is not afraid to introduce structure, halt endless discussions and make decisions in support of the group's objective(s) $[26,54,71]$. In line with research by Compen and Schelfhout [83], we found that external process coaches were not better positioned to adopt such a role and establish the PLC's objectives than was an internal process coach. When participants are acquainted and the PLC's objectives are not too complex (requiring considerable external input), the role of the process coach can easily be adopted by a primus inter pares. A primus inter pares or internal process was furthermore found to have two advantages over an external one. For one, the former seemed better equipped to show a vulnerability that other principals could relate to, inspiring them towards favourable learning behaviour. Two, a primus inter pares can aid to a group's sense of autonomy and ownership, which Stewart [95] found to have a moderately strong relationship with group performance.

However, contrary to a coordinating role, adopting an expert role appeared more intricate. Principals expected to be supplied with new and relevant ideas or insights. Without those, they were unlikely to perceive the PLC outcomes as satisfactory. Yet, in the case of PLC members convening over broad and/or complex policy issues, the expertise internally available might be too limited to guarantee an adequate supply of new information. In those circumstances, an external source of expertise seems indispensable [83]. His or her contributions require careful consideration though as we found these to have the potential to curb LPs—and consequently favourable PLC outcomes [36] - in two ways.

On the one hand, we found that the more the process coach(es) provided answers, the more some principals were inclined to adopt a wait-and-see attitude. They refrained from co-construction, (i.e., by letting the process coach and pedagogical counsellor add on information first) and from critical reflection (i.e., by waiting for both to formulate their objections, comments or thoughts). On the other hand, we also observed how an expert intervention can be experienced as threatening by some participants: Particularly those principals the pedagogical counsellors described as rather weak, chaotic or hesitant school leaders. Those school leaders appeared to block the newly received information as they stuck to a mere repetition of their original story. Something which, of course, slowed down discussions and, consequently, the occurrence of meaningful LPs. Guaranteeing enough input whilst avoiding PLC members becoming overly reliant on that input, therefore proves a precarious balancing exercise for a(n) (external) process coach. 


\section{Limitations and Avenues for Future Research}

Future research can benefit from taking into account some of this study's limitations. As only three cases were observed, it remains to be researched whether this study's findings also hold true on a larger scale. Further, each of our three PLCs convened principals from the small education network of cities and municipalities in Flanders. As this network only represents four percent of all Flemish secondary school leaders, PLCs comprising of otherwise affiliated school leaders might render deviating results. We do, nonetheless, only hypothesise slight, instead of considerable, deviations given recent studies on Flemish school leadership showed principals to face similar challenges (and obstacles) in exercising their jobs $[3,96]$. In this regard, researchers should continue to examine the conditions under which networked principal PLCs can render fruitful results from a distributed leadership point of view and the ways in which these can find an actual transfer to teachers' rooms and classroom floors. A clear need still exists in Flemish secondary education to organise schools according to distributed leadership principles [96].

Furthermore, even though our study followed a longitudinal design, principals within the first two cases met at a relatively low frequency (i.e., approximately once every three months) with a fluctuating attendance rate. Additional longitudinal studies on networked principal PLCs that convene with a higher frequency and a constant attendance rate might yield greater insight and provide more reliable results on alterations in LPs and group development processes, outputs and outcomes over time. It should be noted, however, that the longitudinal character of our research design was also affected by the COVID-19 crisis which curbed several sessions within PLCs 2 and 3. Those unforeseen events required principals to attend to a more urgent myriad of government measures first. The limited and greatly varying amount of observation points per case caused by COVID-19, of course also impacted this research' reliability.

The aforementioned COVID-19 crisis and concomitant government measures also caused one (additional) session to take place digitally within PLC 1. Although we witnessed no substantial difference in LP occurrence and group dynamics as compared to the other sessions, such a digital set-up might influence group learning and development for the better or worse [98]. A comparison of physical, digital and hybrid networked PLC designs might offer an interesting avenue for future research too. Definitely so, since principals occasionally signalized that commuting affected their motivation to partake in a certain session.

\section{Conclusions}

As networked principal PLCs still prove a nascent field of research, this study observed three networked PLCs among Flemish secondary school principals and examined the intricate interaction between goal complexity, CES, LPs and the roles of internal and/or external process coaches. Although PLCs are a time-consuming initiative and principals are easily over-solicited, we found principals to perceive their PLC as a worthwhile time investment. PLCs led to the acquisition of new ideas, a reduction of professional isolation and an increased ability to critically reflect on one's own professional conduct. We discerned three sets of favourable-and even necessary-conditions for LPs to prosper within a PLC and give rise to even more personal outcomes and practical output.

Within the first set, conditions connect to the organisation and structuring of PLC sessions as they include narrowly-defined objective(s) (a) endorsed by each individual member (b) and perceived as logically embedded in his or her professional practice (c). The second set of conditions are situated on a group or community level. They require principals motivated (a) to engage in a safe and trusting community (b) with a profound belief in the reciprocal and positive influence fellow members can have on both the realisation of the group's objective(s) and, one's own and others' professional practice (c). At all times, adequate attention should be paid to group development. Therein, the process coach (and/or external advisor(s)) can play a leading role, which brings us to a third set of conditions: Conditions situated at the level of PLC leadership. PLC functioning was found 
to benefit from role clarity (a) through which a primus inter pares (b) adopted a steering or coordinating role (c). At least, when the group's objective is not too complex or does not involve too professionally sensitive topics.

All conditions were found to predominantly impact a PLC's capacity to stimulate its members to co-construct practical output. Yet, this study also showed that even without all conditions being met, PLCs still prove a suitable CPL initiative when one aimed for outcomes at a personal level. The mere routine of convening and freeing time to discuss policy, take a stance and, collectively learn and professionalise, already adds to parts of principals' professional well-being regardless of its (in)ability to generate practical output. An intriguing constatation as principal professional well-being comprises an essential and prominent theme in contemporary (Flemish) education. From this, we conclude that networked principals PLCs can be a worthwhile investment by policymakers.

Supplementary Materials: The following are available online at https:/ / www.mdpi.com/article/10.339 0/educsci11090509/s1, Table S1: Observation scheme items (Supplementary File A), Table S2: Questionnaire items (Supplementary File B), Topic list interview protocol (Supplementary File C), Table S3: Coding tree interview data with an overview of unique references and sources and, exemplary quotes (Supplementary File D).

Author Contributions: L.C. was responsible for the conceptualisation, investigation, formal analysis, and the writing of the original draft. W.S. supervised the study, participated in the conceptualisation, validated the analyses and reviewed the article. A.H. supervised the study, validated the analyses and reviewed the article. All authors have read and agreed to the published version of the manuscript.

Funding: This work was supported by The Public Governance Institute (KU Leuven) and funded by the Research Foundation Flanders (FWO) under grant number G.0735.17N.

Institutional Review Board Statement: Ethical review and approval were waived for this study due to the non-experimental character of this study. Interviews were, however, accompanied by an informed consent and data was processed and saved according to KU Leuven's data management policy.

Informed Consent Statement: Informed consent was obtained from all subjects involved in the study.

Data Availability Statement: Questionnaire and interview data used in this research was collected subject to the informed consent of the participants. Access to the data will only be granted in line with that consent. Supporting, yet anonymized, data is therefore available on request: please contact the first author.

Acknowledgments: We thank three anonymous reviewers and two colleagues for their valuable suggestions. We are grateful to OVSG for their collaboration.

Conflicts of Interest: The authors declare no conflict of interest.

\section{References}

1. Forde, C. Leadership for Learning: Educating Educational Leaders. In International Handbook of Leadership for Learning; Townsend, T., MacBeath, J., Eds.; Springer: Dordrecht, Switzerland, 2011; Chapter 21; pp. 355-374. [CrossRef]

2. MacBeath, J.; O’Brien, J.; Gronn, P. Drowning or Waving? Coping Strategies among Scottish Head Teachers. Sch. Leadersh. Manag. 2012, 32, 421-437. [CrossRef]

3. Devos, G.; Vanblaere, B.; Bellemans, L. Stress En Welbevinden Bij Schoolleiders: Een Analyse van Bepalende Factoren En van Vereiste Randvoorwaarden; SONO/2017.VrijeRuimte/1; Steunpunt Onderwijsonderzoek: Gent, België, 2018.

4. Leithwood, K.; Harris, A.; Hopkins, D. Seven Strong Claims about Successful School Leadership. Sch. Leadersh. Manag. 2008, 28, 27-42. [CrossRef]

5. Thomas, L.; Tuytens, M.; Devos, G.; Kelchtermans, G.; Vanderlinde, R. Transformational School Leadership as a Key Factor for Teachers' Job Attitudes during Their First Year in the Profession. Educ. Manag. Adm. Leadersh. 2020, 48, 106-132. [CrossRef]

6. OECD. Positive, High-Achieving Students? What Schools and Teachers Can Do; TALIS, OECD Publishing: Paris, France, 2021. [CrossRef]

7. Aas, M.; Vavik, M. Group Coaching: A New Way of Constructing Leadership Identity? Sch. Leadersh. Manag. 2015, 35, 251-265. [CrossRef]

8. MacBeath, J. No Lack of Principles: Leadership Development in England and Scotland. Sch. Leadersh. Manag. 2011, 31, 105-121. [CrossRef] 
9. MacBeath, J.; Dempster, N.; Frost, D.; Johnson, G.; Swaffield, S. Strengthening the Connections between Leadership and Learning: Challenges to Policy, School and Classroom Practice; Routledge: Oxon, UK, 2018. [CrossRef]

10. Hargreaves, A. Teaching in the Knowledge Society; Teachers College Press: New York, NY, USA, 2003.

11. Robinson, V.M.J. Descriptive and Normative Research on Organizational Learning: Locating the Contribution of Argyris and Schön. Int. J. Educ. Manag. 2001, 15, 58-67. [CrossRef]

12. Sigurðardóttir, A.K. Studying and Enhancing Professional Learning Community for School Effectiveness in Iceland. Rev. Iberoam. Sobre Calid. Efic. Cambio Educ. 2005, 3, 178-193.

13. Aas, M. Professional Development in Education Leaders as Learners: Developing New Leadership Practices. Prof. Dev. Educ. 2017, 5257, 1-15. [CrossRef]

14. Daniëls, E.; Hondeghem, A.; Heystek, J. Developing School Leaders: Responses of School Leaders to Group Reflective Learning. Prof. Dev. Educ. 2020, 1-15. [CrossRef]

15. Slotte, V.; Tynjälä, P.; Hytönen, T. How Do HRD Practitioners Describe Learning at Work? Hum. Resour. Dev. Int. 2004, 7, 481-499. [CrossRef]

16. Simkins, T. Understanding School Leadership and Management Development in England. Educ. Manag. Adm. Leadersh. 2012, 40, 621-640. [CrossRef]

17. Wright, L.; da Costa, J. Rethinking Professional Development for School Leaders: Possibilities and Tensions. J. Educ. Adm. Found. 2016, 25, 29-47.

18. Huber, S.G. Multiple Learning Approaches in the Professional Development of School Leaders-Theoretical Perspectives and Empirical Findings on Self-Assessment and Feedback. Educ. Manag. Adm. Leadersh. 2013, 41, 527-540. [CrossRef]

19. Goldring, E.; Preston, C.; Huff, J. Conceptualizing and Evaluating Professional Development for School Leaders. Plan. Chang. 2012, 43, 223-242.

20. Huber, S.G. The Impact of Professional Development: A Theoretical Model for Empirical Research, Evaluation, Planning and Conducting Training and Development Programmes. Prof. Dev. Educ. 2011, 37, 837-853. [CrossRef]

21. Hulsbos, F.A.; Evers, A.T.; Kessels, J.W.M. Learn to Lead: Mapping Workplace Learning of School Leaders. Vocat. Learn. 2016, 9 , 21-42. [CrossRef]

22. Bush, T. Preparation and Induction for School Principals: Global Perspectives. Manag. Educ. 2018, 32, 66-71. [CrossRef]

23. Daniëls, E.; Hondeghem, A.; Dochy, F. An Integrative Perspective on Leadership and Leadership Development in an Educational Setting: A Systematic Review. Educ. Res. Rev. 2019, 27, 1-22. [CrossRef]

24. Pont, B.; Nusche, D.; Hopkins, D. Improving School Leadership; Policy and Practice; OECD: Paris, France, 2008 ; Volume 1.

25. Hairon, S.; Goh, J.W.P.; Chua, C.S.K.; Wang, L. A Research Agenda for Professional Learning Communities: Moving Forward. Prof. Dev. Educ. 2017, 43, 72-86. [CrossRef]

26. Prenger, R.; Poortman, C.L.; Handelzalts, A. The Effects of Networked Professional Learning Communities. J. Teach. Educ. 2018, 70, 441-452. [CrossRef]

27. Prenger, R.; Poortman, C.L.; Handelzalts, A. Factors Influencing Teachers' Professional Development in Networked Professional Learning Communities. Teach. Teach. Educ. 2017, 68, 77-90. [CrossRef]

28. Vanblaere, B.; Devos, G. The Role of Departmental Leadership for Professional Learning Communities. Educ. Adm. Q. 2018, 54, 85-114. [CrossRef]

29. Vanblaere, B.; Devos, G. Relating School Leadership to Perceived Professional Learning Community Characteristics: A Multilevel Analysis. Teach. Teach. Educ. 2016, 57, 26-38. [CrossRef]

30. Louis, K.S.; Marks, H.M. Does Professional Community Affect the Classroom? Teachers' Work and Student Experiences in Restructuring Schools. Am. J. Educ. 1998, 106, 532-575. [CrossRef]

31. Voogt, J.; Laferrière, T.; Breuleux, A.; Itow, R.C.; Hickey, D.T.; McKenney, S. Collaborative Design as a Form of Professional Development. Instr. Sci. 2015, 43, 259-282. [CrossRef]

32. Voogt, J.; Westbroek, H.; Handelzalts, A.; Walraven, A.; Mckenney, S.; Pieters, J.; Vries, B. De. Teacher Learning in Collaborative Curriculum Design. Teach. Teach. Educ. 2011, 27, 1235-1244. [CrossRef]

33. Vangrieken, K.; Dochy, F.; Raes, E. Team Learning in Teacher Teams: Team Entitativity as a Bridge between Teams-in-Theory and Teams-in-Practice. Eur. J. Psychol. Educ. 2016, 31, 275-298. [CrossRef]

34. Vangrieken, K.; Meredith, C.; Packer, T.; Kyndt, E. Teacher Communities as a Context for Professional Development: A Systematic Review. Teach. Teach. Educ. 2017, 61, 47-59. [CrossRef]

35. Chapman, C.; Muijs, D. Does School-to-School Collaboration Promote School Improvement ? A Study of the Impact of School Federations on Student Outcomes. Sch. Eff. Sch. Improv. 2014, 25, 351-393. [CrossRef]

36. Honig, M.I.; Rainey, L.R. Central Office Leadership in Principal Professional Learning Communities: The Practice beneath the Policy. Teach. Coll. Rec. 2014, 116, 1-48.

37. Van der Haar, S.; Segers, M.; Jehn, K.; Van den Bossche, P. Investigating the Relation Between Team Learning and the Team Situation Model. Small Group Res. 2015, 46, 50-82. [CrossRef]

38. Raes, E.; Decuyper, S.; Lismont, B.; Van den Bossche, P.; Kyndt, E.; Demeyere, S.; Dochy, F. Facilitating Team Learning through Transformational Leadership. Instr. Sci. 2013, 41, 287-305. [CrossRef]

39. Van den Bossche, P.; Gijselaers, W.H.; Segers, M.; Kirschner, P.A. Social and Cognitive Factors Driving Teamwork in Collaborative Learning Environments: Team Learning Beliefs and Behaviors. Small Group Res. 2006, 37, 490-521. [CrossRef] 
40. Minea-Pic, A.; Nusche, D.; Sinnema, C.; Stoll, L. Teachers' Professional Learning Study: Diagnostic Report for the Flemish Community of Belgium; OECD Publishing: Paris, France, 2021. [CrossRef]

41. Stoll, L.; Bolam, R.; McMahon, A.; Wallace, M.; Thomas, S. Professional Learning Communities: A Review of the Literature. J. Educ. Chang. 2006, 7, 221-258. [CrossRef]

42. Van den Bossche, P.; Gijselaers, W.; Segers, M.; Woltjer, G.; Kirschner, P. Team Learning: Building Shared Mental Models. Instr. Sci. 2011, 39, 283-301. [CrossRef]

43. Cooke, N.J.; Salas, E.; Cannon-Bowers, J.A.; Stout, R.J. Measuring Team Knowledge. Hum. Factors 2000, 42, 151-173. [CrossRef]

44. Bolam, R.; Mcmahon, A.; Stoll, L.; Thomas, S.; Wallace, M.; Greenwood, A.; Hawkey, K.; Ingram, M.; Atkinson, A.; Smith, M. Creating and Sustaining Effective Professional Learning Communities; DfES Publications: Nottingham, UK, 2005.

45. Hord, S.M. Evolution of the Professional Learning Community. J. Staff Dev. 2008, 29, 10-13.

46. Vescio, V.; Ross, D.; Adams, A. A Review of Research on the Impact of Professional Learning Communities on Teaching Practice and Student Learning. Teach. Teach. Educ. 2008, 24, 80-91. [CrossRef]

47. DuFour, R. What Is a "Professional Learning Community"? Educ. Leadersh. 2004, 61, 6-11.

48. Flückiger, B.; Aas, M.; Nicolaidou, M.; Johnson, G.; Lovett, S. Professional Development in Education the Potential of Group Coaching for Leadership Learning. Prof. Dev. Educ. 2017, 43, 612-629. [CrossRef]

49. Lomos, C.; Hofman, R.H.; Bosker, R.J. Professional Communities and Student Achievement-A Meta-Analysis. Sch. Eff. Sch. Improv. 2011, 22, 3453. [CrossRef]

50. Desimone, L.M. Improving Impact Studies of Teachers' Professional Development: Toward Better Conceptualizations and Measures. Educ. Res. 2009, 38, 181-199. [CrossRef]

51. Sutherland, S.; Katz, S. Concept Mapping Methodology: A Catalyst for Organizational Learning. Eval. Program Plan. 2005, 28, 257-269. [CrossRef]

52. Hord, S.M. Learning Together, Leading Together: Changing Schools through Professional Learning Communities; Teachers College Press: New York, NY, USA, 2004.

53. Newmann, F.M.; Wehlage, G.G. Successful School Restructuring: A Report to the Public and Educators; Center on Organization and Restructuring of Schools: Madison, WI, USA, 1995.

54. Brown, S.W.; Grant, A.M. From Grow to Group: Theoretical Issues and a Practical Model for Group Coaching in Organisations. Coaching 2010, 3, 30-45. [CrossRef]

55. Cohen, S.G.; Bailey, D.E. What Makes Teams Work: Group Effectiveness Research from the Shop Floor to the Executive Suite. J. Manag. 1997, 23, 239-290. [CrossRef]

56. Raes, E.; Kyndt, E.; Decuyper, S.; Van den Bossche, P.; Dochy, F. An Exploratory Study of Group Development and Team Learning. Hum. Resour. Dev. Q. 2015, 26, 5-30. [CrossRef]

57. Schelfhout, W. Toward Data for Development: A Model on Learning Communities as a Platform for Growing Data Use. In Data Analytics Applications in Education; Vanthienen, J., De Witte, K., Eds.; Taylor \& Francis Group: Boca Raton, FL, USA, 2017; pp. 37-82.

58. McLaughlin, M.W.; Talbert, J.E. Professional Communities and the Work of High School Teaching; University of Chicago Press: Chicago, IL, USA, 2001.

59. Gray, J.; Kruse, S.; Tarter, C.J. Enabling School Structures, Collegial Trust and Academic Emphasis: Antecedents of Professional Learning Communities. Educ. Manag. Adm. Leadersh. 2016, 44, 875-891. [CrossRef]

60. Edmondson, A. Psychological Safety and Learning Behavior in Work Teams. Adm. Sci. Q. 1999, 44, 350-383. [CrossRef]

61. Decuyper, S.; Dochy, F.; Van den Bossche, P. Grasping the Dynamic Complexity of Team Learning: An Integrative Model for Effective Team Learning in Organisations. Educ. Res. Rev. 2010, 5, 111-133. [CrossRef]

62. Baker, M.J. A Model for Negotiation in Teaching-Learning Dialogues. Int. J. Artif. Intell. Educ. 1994, 5, $199-254$.

63. Hargreaves, A. (Ed.) Teaching in the Knowledge Society: Education in the Age of Insecurity; Open University Press: Maidenhead, UK, 2004.

64. Wenger, E. Communities of Practice: Learning, Meaning, and Identity; Cambridge University Press: Cambridge, UK, 2008.

65. Salomon, G.; Globerson, T. When Teams Do Not Function the Way They Ought To. Int. J. Educ. Res. 1989, 13, 89-99. [CrossRef]

66. Bryk, A.S.; Schneider, B. Trust in Schools: A Core Resource for Improvement (Rose Series in Sociology); Russell Sage Foundation: New York, NY, USA, 2002.

67. Van der Vegt, G.; Emans, B.; Van de Vliert, E. Motivating Effects of Task and Outcome Interdependence in Work Teams. Group Organ. Manag. 1998, 23, 124-143. [CrossRef]

68. Vangrieken, K.; Boon, A.; Dochy, F.; Kyndt, E. Group, Team, or Something in between? Conceptualising and Measuring Team Entitativity. Front. Learn. Res. 2017, 5, 1-41. [CrossRef]

69. Clutterbuck, D. Coaching the Team at Work; Nicholas Brealey International: London, UK, 2007.

70. Avgitidou, S. Participation, Roles and Processes in a Collaborative Action Research Project: A Reflexive Account of the Facilitator. Educ. Action Res. 2009, 17, 585-600. [CrossRef]

71. Schelfhout, W.; Bruggeman, K.; Bruyninckx, M. Vakdidactische Leergemeenschappen, Een Antwoord Op Professionaliseringsbehoeften Bij Leraren Voortgezet Onderwijs? Eindhoven 2015, 36, 63-82.

72. Margalef, L.; Roblin, N.P. Unpacking the Roles of the Facilitator in Higher Education Professional Learning Communities. Educ. Res. Eval. 2016, 22, 155-172. [CrossRef] 
73. Zonoubi, R.; Eslami Rasekh, A.; Tavakoli, M. EFL Teacher Self-Efficacy Development in Professional Learning Communities. System 2017, 66, 1-12. [CrossRef]

74. Brandmo, C.; Aas, M.; Colbjørnsen, T.; Olsen, R. Group Coaching That Promotes Self-Efficacy and Role Clarity among School Leaders. Scand. J. Educ. Res. 2021, 65, 195-211. [CrossRef]

75. Devos, G.; Van Petegem, P.; Delvaux, E.; Feys, E.; Franquet, A. De Evaluatie van Scholengemeenschappen in Het Basis-En Secundair Onderwijs; OBPWO-Project 07.02; Ministerie van de Vlaamse Gemeenschap: Brussel, België, 2010.

76. Weißenrieder, J.; Roesken-Winter, B.; Schueler, S.; Binner, E.; Blömeke, S. Scaling CPD through Professional Learning Communities: Development of Teachers' Self-Efficacy in Relation to Collaboration. ZDM Math. Educ. 2015, 47, 27-38. [CrossRef]

77. Aas, M.; Paulsen, J.M. National Strategy for Supporting School Principal' s Instructional Leadership A Scandinavian Approach. J. Educ. Adm. 2019, 57, 540-553. [CrossRef]

78. Lazenby, S.; McCulla, N.; Marks, W. The Further Professional Development of Experienced Principals. Int. J. Leadersh. Educ. 2020, 1-15. [CrossRef]

79. Tomic, W.; Tomic, E. Existential Fulfillment and Burnout among Principals and Teachers. J. Beliefs Values 2008, 29, 11-27. [CrossRef]

80. Stephenson, L.E.; Bauer, S.C. The Role of Isolation in Predicting New Principals' Burnout. Int. J. Educ. Policy Leadersh. 2010, 5, 1-17. [CrossRef]

81. Fluckiger, B.; Lovett, S.; Dempster, N. Judging the Quality of School Leadership Learning Programmes: An International Search. Prof. Dev. Educ. 2014, 40, 561-575. [CrossRef]

82. Bouchamma, Y.; Michaud, C. Professional Development of Supervisors through Professional Learning Communities. Int. J. Leadersh. Educ. 2014, 17, 62-82. [CrossRef]

83. Compen, B.; Schelfhout, W. The Role of External and Internal Team Coaches in Teacher Design Teams. A Mixed Methods Study. Educ. Sci. 2020, 10, 263. [CrossRef]

84. Borko, H. Professional Development and Teacher Learning: Mapping the Terrain. Educ. Res. 2004, 33, 3-15. [CrossRef]

85. Binkhorst, F.; Poortman, C.L.; van Joolingen, W.R. A Qualitative Analysis of Teacher Design Teams: In-Depth Insights into Their Process and Links with Their Outcomes. Stud. Educ. Eval. 2017, 55, 135-144. [CrossRef]

86. Van Waes, S.; Moolenaar, N.M.; Daly, A.J.; Heldens, H.H.P.F.; Donche, V.; Van Petegem, P.; Van den Bossche, P. The Networked Instructor: The Quality of Networks in Different Stages of Professional Development. Teach. Teach. Educ. 2016, 59, 295-308. [CrossRef]

87. Duncan, H.E.; Stock, M.J. Mentoring and Coaching Rural School Leaders: What Do They Need? Mentor. Tutoring Partnersh. Learn. 2010, 18, 293-311. [CrossRef]

88. Daresh, J.C.; Alexander, L. Beginning the Principalship: A Practical Guide for New School Leaders; Corwin Press: Thousand Oaks, CA, USA, 2016. [CrossRef]

89. Robertson, S. Transformation of Professional Identity in an Experienced Primary School Principal. Educ. Manag. Adm. Leadersh. 2017, 45, 774-789. [CrossRef]

90. Leithwood, K.; Azah, V.N. Characteristics of Effective Leadership Networks. J. Educ. Adm. 2016, 54, 409-433. [CrossRef]

91. Wahl, D. Nachhaltige Wege Vom Wissen Zum Handeln. Beiträge zur Lehrerinnen-und Lehrerbildung 2001, 19, 157-174.

92. Handelzalts, A. Collaborative Curriculum Development in Teacher Design Teams. In Collaborative Curriculum Design for Sustainable Innovation and Teacher Learning; Pieters, J., Voogt, J., Roblin, N.P., Eds.; Springer: Cham, Switzerland, 2019; pp. 159-173. [CrossRef]

93. Vangrieken, K.; Dochy, F.; Raes, E.; Kyndt, E. Teacher Collaboration: A Systematic Review. Educ. Res. Rev. 2015, 15, 17-40. [CrossRef]

94. Peterson, K. The Professional Development of Principals: Innovations and Opportunities. Educ. Adm. Q. 2002, 38, 213-232. [CrossRef]

95. Stewart, G.L. A Meta-Analytic Review of Relationships between Team Design Features and Team Performance. J. Manag. 2006, 32, 29-55. [CrossRef]

96. Coenen, L.; Hondeghem, A.; Schelfhout, W. The Emergence of Leadership for Learning Beliefs among Flemish Secondary School Leaders. Int. J. Leadersh. Educ. 2021, 1-19. [CrossRef]

97. Herrmann, M.; Clark, M.; James-Burdumy, S.; Tuttle, C.; Kautz, T.; Knechtel, V.; Dotter, D.; Wulsin, C.S.; Deke, J. The Effects of a Principal Professional Development Program Focused on Instructional Leadership; NCEE 2020-0002; Institute of Education Sciences: Washington, DC, USA, 2019.

98. DeFilippis, E.; Impink, S.; Singell, M.; Polzer, J.T.; Sadun, R. Collaborating During Coronavirus: The Impact of COVID-19 on the Nature of Work. SSRN Electron. J. 2020. [CrossRef] 